\title{
Rbm8a Haploinsufficiency Disrupts Embryonic Cortical Development Resulting in Microcephaly
}

\author{
Hanqian Mao, ${ }^{1}$ Louis-Jan Pilaz, ${ }^{1}$ John J. McMahon, ${ }^{1}{ }^{\mathbb{C} C h r i s t e l l e ~ G o l z i o,},{ }^{2,3}$ Danwei Wu, ${ }^{1}$ Lei Shi, ${ }^{1}$ \\ Nicholas Katsanis, ${ }^{2,4}$ and DDebra L. Silver ${ }^{1,4,5,6}$ \\ ${ }^{1}$ Department of Molecular Genetics and Microbiology, Duke University Medical Center, Durham, North Carolina 27710, ${ }^{2}$ Center for Human Disease \\ Modeling, Duke University Medical Center, Durham, North Carolina 27701, ${ }^{3}$ Department of Psychiatry and Behavioral Sciences, ${ }^{4}$ Department of Cell \\ Biology, ${ }^{5}$ Department of Neurobiology, and ${ }^{6}$ Duke Institute for Brain Sciences, Duke University Medical Center, Durham, North Carolina 27710
}

The cerebral cortex is built during embryonic neurogenesis, a period when excitatory neurons are generated from progenitors. Defects in neurogenesis can cause acute neurodevelopmental disorders, such as microcephaly (reduced brain size). Altered dosage of the 1q21.1 locus has been implicated in the etiology of neurodevelopmental phenotypes; however, the role of 1q21.1 genes in neurogenesis has remained elusive. Here, we show that haploinsufficiency for Rbm8a, an exon junction complex (EJC) component within 1q21.1, causes severe microcephaly and defective neurogenesis in the mouse. At the onset of neurogenesis, $R b m 8 a$ regulates radial glia proliferation and prevents premature neuronal differentiation. Reduced $R b m 8 a$ levels result in subsequent apoptosis of neurons, and to a lesser extent, radial glia. Hence, compared to control, Rbm8a-haploinsufficient brains have fewer progenitors and neurons, resulting in defective cortical lamination. To determine whether reciprocal dosage change of $R b m 8 a$ alters embryonic neurogenesis, we overexpressed human $R B M 8 A$ in two animal models. Using in utero electroporation of mouse neocortices as well as zebrafish models, we find $R B M 8 A$ overexpression does not significantly perturb progenitor number or head size. Our findings demonstrate that $R b m 8 a$ is an essential neurogenesis regulator, and add to a growing literature highlighting roles for EJC components in cortical development and neurodevelopmental pathology. Our results indicate that disruption of $R B M 8 A$ may contribute to neurodevelopmental phenotypes associated with proximal 1q21.1 microdeletions.

Key words: cortical development; embryonic; microcephaly; neurogenesis; radial glia; rbm8a

\section{Introduction}

During embryonic cortical development, progenitor populations undergo neurogenesis, producing excitatory neurons that ultimately contribute to the six-layered mature neocortex (Franco and Müller, 2013; Greig et al., 2013). In mice, neurogenesis begins at $\sim$ E10.5 and continues through the end of embryogenesis. The earliest progenitors are neuroepithelial cells, which differentiate into radial glia by E11.5. Radial glial cells undergo selfrenewal divisions, and as development proceeds, switch to neurogenic divisions to generate new radial glia and either a neuron or a neuron-producing intermediate progenitor (IP; Noctor et al., 2001; Englund et al., 2005; Kowalczyk et al., 2009; Vasistha

Received Dec. 31, 2014; revised March 8, 2015; accepted March 27, 2015.

Author contributions: H.M. and D.L.S. designed research; H.M., L.-J.P., J.J.M., C.G., D.W., L.S., and D.L.S. performed research;H.M., L.-J.P., J.J.M., C.G., D.W., L.S., N.K., and D.L.S. analyzed data; H.M. and D.L.S. wrote the paper.

This work was supported by National Institutes of Health (NIH) grants to D.L.S. (R01NS083897 and R00NS064197), AHA 13PRE17070078 Predoctoral Fellowship and Broad Graduate student Award to H.M., SFARI 239983 and NIH P50MH094268 to N.K., and National Alliance for Research on Schizophrenia and Depression Young Investigator Award to C.G., N.K. is a Distinguished Brumley Professor. We thank Autumn Rorrer for assistance with mouse husbandry, Chad Russel and Jason Willer for technical assistance for zebrafish experiments, members of the Silver lab for useful insights and helpful discussions, and Cagla Eroglu for critical reading of the manuscript.

The authors declare no competing financial interests.

Correspondence should be addressed to Debra L. Silver, 224 CARL Building, Box 3175, 213 Research Drive, Durham, NC 27710. E-mail: debra.silver@duke.edu.

DOI:10.1523/JNEUROSCI.0018-15.2015

Copyright $\odot 2015$ the authors $\quad 0270-6474 / 15 / 357003-16 \$ 15.00 / 0$ et al., 2014). Defective progenitor proliferation or excessive apoptosis can skew neuron number and ultimately alter mature brain size and function (Silver et al., 2010; Lancaster et al., 2013; Marthiens et al., 2013; Insolera et al., 2014). Thus, aberrant neurogenesis can cause severe neurodevelopmental disorders including microcephaly (small brain size accompanied by cognitive impairment; Hu et al., 2014). Understanding the genes regulating neurogenesis is a high priority to elucidate the etiology of neurodevelopmental diseases.

Recent studies from our lab and others have demonstrated critical roles for the exon junction complex (EJC) in neurogenesis and neurodevelopmental pathology. The core EJC, composed of MAGOH, EIF4A3, and RBM8A, binds mRNA and regulates RNA metabolism (Kataoka et al., 2001; Palacios et al., 2004; Shibuya et al., 2004; Ashton-Beaucage et al., 2010; Roignant and Treisman, 2010). We showed previously that Magoh haploinsufficiency in mice causes microcephaly due to IP depletion and neuronal apoptosis (Silver et al., 2010; McMahon et al., 2014). Subsequent human genetic studies revealed copy number variations (CNVs) of EJC components, EIF4A3 and RBM8A, associated with intellectual disability and brain malformations (Nguyen et al., 2013). $R B M 8 A$ is one of 16 genes in the 1q21.1 proximal region [breakpoint (BP) 2-BP3], located adjacent to the 1q21.1 distal region (BP3-BP4). Microdeletions and duplications of either region are associated with neurodevelopmental phenotypes including brain 
size abnormalities and autism spectrum disorders; however, the causative gene(s) remain unknown (Brunetti-Pierri et al., 2008; International Schizophrenia Consortium, 2008; Mefford et al., 2008; Rosenfeld et al., 2012). Additionally, compound RBM8A mutations (null plus a noncoding mutation) cause thrombocytopenia-absent radius (TAR) syndrome, a blood skeletal disorder in which $7 \%$ of patients also exhibit cognitive impairments and brain malformations (Albers et al., 2012; Rosenfeld et al., 2012; Nguyen et al., 2014). Although there is strong evidence that RBMA8A causes TAR syndrome, it remains undetermined whether $R B M A 8 A$ also contributes to neurodevelopmental phenotypes.

Here we examined the requirement of $R b m 8 a$ in embryonic brain development. Using a novel conditional mouse allele, we show that Rbm8a depletion in the dorsal telencephalon causes severe microcephaly due to neurogenesis defects affecting progenitor proliferation, progenitor and neuron number, and apoptosis. Additionally, using zebrafish models and in utero electroporation of mouse embryos, we demonstrate $R B M 8 A$ overexpression does not significantly perturb progenitor number or head size. Our findings show $R b m 8 a$ is critical for proper cortical development, revealing that $R B M 8 A$ haploinsufficiency may be a major driver for microcephaly in individuals with proximal 1q21.1 deletions.

\section{Materials and Methods}

Mouse husbandry and generation of conditional Rbm8a allele. All experiments were performed in agreement with the guidelines from the Division of Laboratory Animal Resources from Duke University School of Medicine and Institutional Animal Care and Use Committee. Plug dates were defined as E0.5 on the morning the plug was identified. The conditional targeting vector for ES cell targeting was designed and generated by the Transgenic Facility at Duke University Cancer center. Positive ES clones were selected by performing long-range PCR of both arms. For long-range PCR of $5^{\prime}$ arms, the following conditions were used: $94^{\circ} \mathrm{C} \times$ $2 \mathrm{~min}(1 \times) ; 98^{\circ} \mathrm{C} \times 15 \mathrm{~s}, 60^{\circ} \mathrm{C} \times 15 \mathrm{~s}, 68^{\circ} \mathrm{C} \times 7.5 \mathrm{~min}(40 \times) ; 72^{\circ} \mathrm{C} \times 7$ min. 5' F1: ATGCCTCCCTTCTAAGACAGGCTG; 5' R1: AAGGGTTATTGAATATGATCGGAATTGG. For long-range PCR of $3^{\prime}$ arms, the following conditions were used: $94^{\circ} \mathrm{C} \times 2 \min (1 \times) ; 98^{\circ} \mathrm{C} \times 15 \mathrm{~s}, 60^{\circ} \mathrm{C} \times$ $15 \mathrm{~s}, 68^{\circ} \mathrm{C} \times 2.5 \mathrm{~min}(40 \times) ; 72^{\circ} \mathrm{C} \times 10 \mathrm{~min} .3^{\prime} \mathrm{F} 1$ :CATTCGCCTTCTTGACGAGTTCTTC; $3^{\prime}$ R1:GTCTGCTCTTCCAGCTCACAACTG. Positive clones were electroporated into C57BL/6J blastocysts, and the chimeras were mated to C57BL/6J females to obtain germline transmission. All experiments to analyze this line were done on an inbred C57BL/6J background. For genotyping $R b m 8 a^{\text {loxp }}$ mice, the following conditions were used: $94^{\circ} \mathrm{C} \times 2 \min (1 \times) ; 94^{\circ} \mathrm{C} \times 15 \mathrm{~s}, 58^{\circ} \mathrm{C} \times 30 \mathrm{~s}$, $72^{\circ} \mathrm{C} \times 30 \mathrm{~s}(30 \times) ; 72^{\circ} \mathrm{C} \times 7 \mathrm{~min}(1 \times)$. LoxF1: CGGACGTGCTGGATCTTCAC; LoxR1: GCACACAGACTCCCCATAGG. The following strain was acquired from The Jackson Laboratory: Emx1-Cre (B6.129S2$\operatorname{Emxl}^{\mathrm{tml}}$ (cre) Krj/J).

Western blot and qRT-PCR analysis. E11.5 embryonic cortices were collected from Emx1-Cre and Emx1-Cre;Rbm8a $a^{\text {loxp } /+}$ mice and lysed in RIPA lysis buffer with protease inhibitors (Pierce). Cortical lysates were run on $4-20 \%$ precasted SDS-polyacrylamide gels (Bio-Rad). Gels were transferred onto nitrocellulose membranes and blotted using the following primary antibodies: rabbit anti-Rbm8a (1:200; Bethyl Laboratories), mouse anti-Rbm8a (1:200; Novus), and mouse anti- $\alpha$-tubulin (1:10,000; Sigma). Blots were developed using ECL reagent (Pierce). Densitometry was performed using ImageJ. Final values were quantified by normalizing Rbm8a levels to loading controls (tubulin) and analyzed for significance using a Student's $t$ test. E10.5, E11.5, E12.5, and E14.5 embryonic cortices were collected from C57BL/6J (wild-type), Emx1-Cre, and Emx1-Cre;Rbm8a $a^{\text {loxp } /+}$ embryos and RNA was extracted using the RNeasy kit (Qiagen). At E10.5 the entire cortex was used, whereas at all other ages, only dorsal neocortex was included. DNA was prepared according to the iScript kit (Bio-Rad). qPCR was performed in triplicates using TaqMan probes (Life Technologies): Rbm8a (Mm04214345_s1),
Pax6 (Mm00443081_m1), and Gapdh (4352339E). For wild-type samples at different developmental stages, absolute qRT-PCR was performed. A standard curve was generated with a five serial 10-fold dilution of cDNA from an independent E14.5 wild-type embryo. For E10.5 and E12.5 Emx1-Cre and Emx1-Cre;Rbm8a $a^{\text {loxp } /+}$ samples comparative qRT-PCR was performed. Values were normalized to Gapdh control. For each genotype three embryos were examined.

Immunohistochemistry and quantification. Brains were fixed overnight in $4 \%$ PFA at $4{ }^{\circ} \mathrm{C}$, followed by submersion in $30 \%$ sucrose until sinking, as previously described (Silver et al., 2010). Brain cryostat sections (20 $\mu \mathrm{m}$ ) were prepared and stored at $-80^{\circ} \mathrm{C}$ until use. Sections were permeabilized with $0.25 \%$ Triton X-100 for 10 min and blocked with MOM block reagent (Vector Laboratories) for $1 \mathrm{~h}$ at room temperature (RT). Sections were incubated with primary antibodies for $2 \mathrm{~h}$ at RT or overnight at $4^{\circ} \mathrm{C}$. Sections were then incubated in species-appropriate secondary antibodies and Hoechst for $15 \mathrm{~min}$ at room temperature. The following primary antibodies were used: rabbit anti-CC3 (diluted 1:200; Cell Signaling Technology), rabbit anti-Tbr2 (1:1000; Abcam), rabbit anti-Pax6 (1:1000; Millipore), rabbit anti-Rbm8a (1:200; Bethyl Laboratories), mouse anti-Pax6 (1:50; Developmental Studies Hybridoma Bank), rabbit anti-Tbr1 (1:200; Abcam), rabbit anti-Foxp1 (1:200; Abcam), rabbit anti-Cux1 (1:100; Santa Cruz Biotechnology), mouse antiTuJ1 (1:400; Covance), mouse anti-Flag (1:200; Sigma), and chicken anti-GFP (1:2000; Abcam). The following secondary antibodies were used: Alexa Fluor 488, 568, 594, 647 (1:200; Invitrogen). TUNEL staining was done in accordance with the manufacturer's directions using an ApopTag fluorescein in situ apoptosis kit (Millipore). Highmagnification images were captured using a Zeiss Axio Observer Z.1 microscope coupled with an apotome. Cortical thickness was measured with Zen software. Cell quantification was performed with ImageJ. Three sections from anatomically comparable regions per embryo and three biological replicates from control (Emx1-Cre) and mutant (Emxl-Cre; $\left.R b m 8 a^{\text {loxp } /+}\right)$ were measured/quantified.

Primary progenitor analysis. E11.5-E14.5 embryonic dorsal cortices were dissected and dissociated with $0.25 \%$ Trypsin-EDTA (Life Technologies) at $37^{\circ} \mathrm{C}$ for $5 \mathrm{~min}$ and triturated with flame-polished Pasteur glass pipette. Dissociated cells were washed once with RT PBS and plated on poly-D-lysine-coated coverslips in 6-well culture dishes. Cells were incubated in DMEM $(1 \times)$ culture media (Life Technologies) supplemented with B27, N2, bFGF, and $N$-acetyl-L-cysteine (Sun et al., 2005) at $37^{\circ} \mathrm{C}$ with $5 \% \mathrm{CO}_{2}$ for $3 \mathrm{~h}$. Cells were then fixed with 4\% PFA for $10 \mathrm{~min}$ before staining with any of the following: rabbit anti-Rbm8a (1:200; Bethyl Laboratories), mouse anti-Pax6 (1:50; Developmental Studies Hybridoma Bank), rabbit anti-Pax6 (1:1000; Millipore), mouse anti-TuJ1 (1: 1000; Covance), and Hoechst. For EdU analysis, cortical cells were dissociated and allowed to settle for an hour in culture media. Cells were pulsed with $10 \mu \mathrm{m}$ EdU for 30 min according to manufacturer's protocol (Life Technologies). Cells were incubated for $24 \mathrm{~h}$ then EdU detection was performed using Click-iT EdU Alexa Fluor 647 Imaging Kit (Life Technologies) and costained with rabbit anti-Ki67 (1:200; Vector Laboratories), mouse anti-TuJ1 (1:1000; Covance), and Hoechst. For all primary cell analysis, high-magnification images were captured using a Zeiss Axio Observer Z.1 microscope coupled with an apotome. Cell quantification was performed with ImageJ.

In utero electroporation. Gene transfer into embryonic wild-type mice was done by in utero electroporation as described with the Harvard apparatus BTX electroporator (Saito, 2006). E13.5 embryos were electroporated with $2.7 \mu \mathrm{g}$ of DNA in a total volume of $1 \mu \mathrm{l}(2 \mu \mathrm{g}$ of either pCAGGS-EX or pCAGGS-Flag-RBM8A accompanied by $0.7 \mu \mathrm{g}$ of pCAGGS-EGFP). E16.5 embryonic brains were prepared as described above. Flag-RBM8A was subcloned into a pCAGGS vector from a $p C L$ Flag- $R B M 8 A$ vector, a gift from Dr. Niels Gehring. Graphs include analyses of the following: $p C A G G S-E X$ plus $p C A G G S-E G F P(n=9-11$ sections, three to four brains) and $p C A G G S$-Flag-RBM8A plus $p C A G G S$ $\operatorname{EGFP}(n=9$ sections, three brains).

Zebrafish analysis. The full-length cDNA of RBM8A was obtained from Life Technologies (Clone ID 10383, ultimate ORF collection) and was cloned into pCS2 vector. Capped mRNA was synthesized in vitro using the mMessage mMachine SP6 kit (Life Technologies; AM1340). We in- 
A

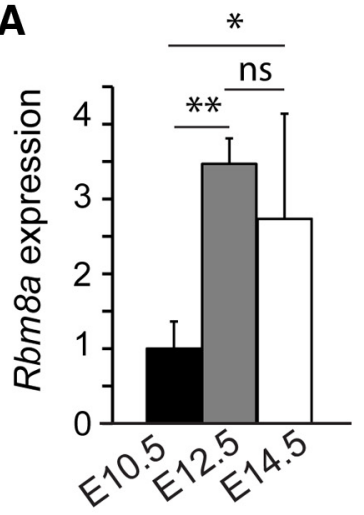

B

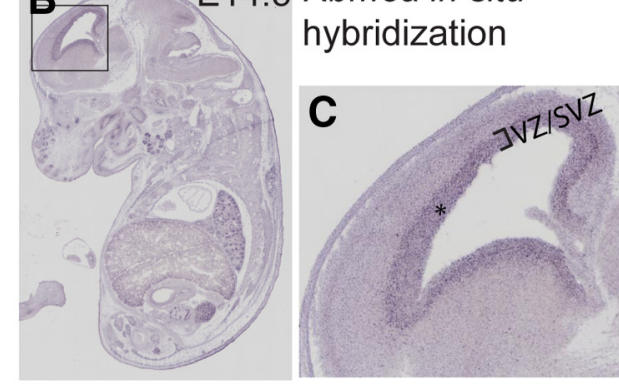

E12.5
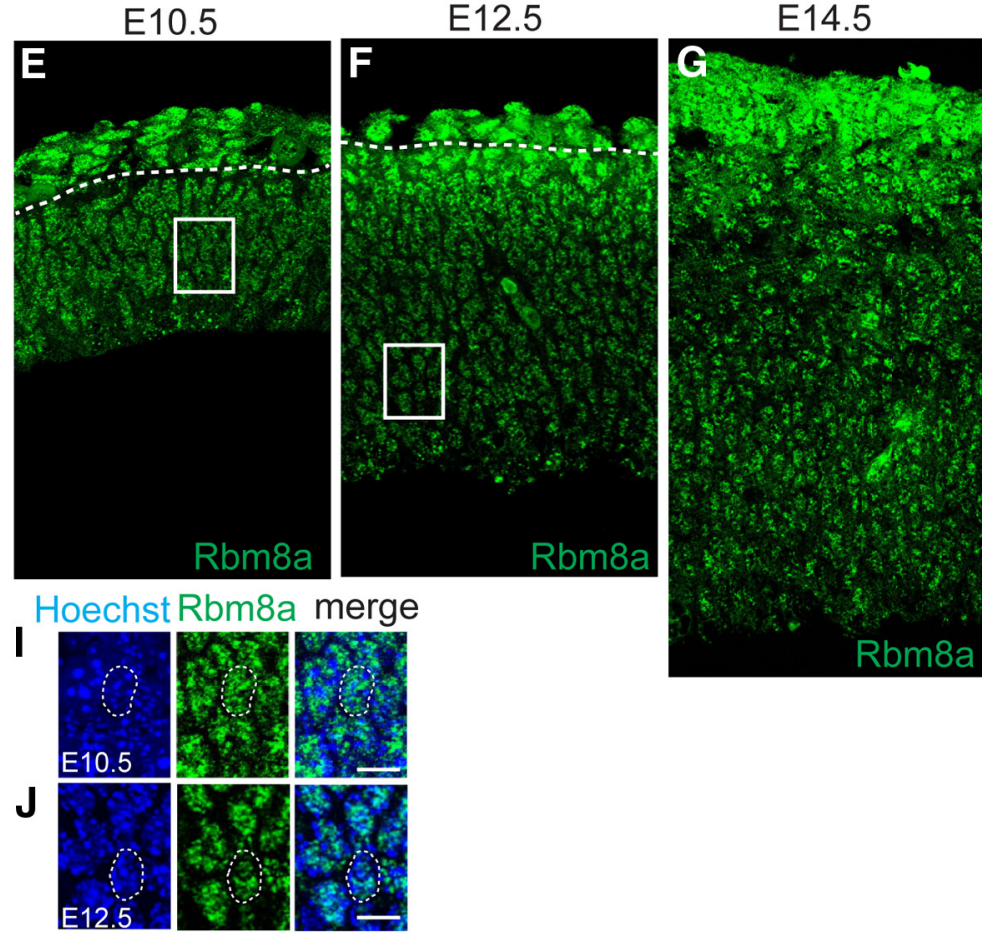

D
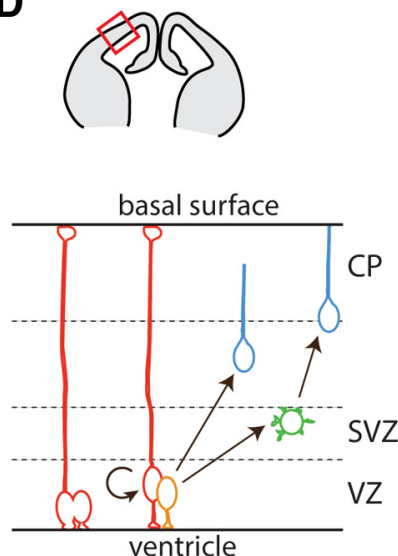

E14.5

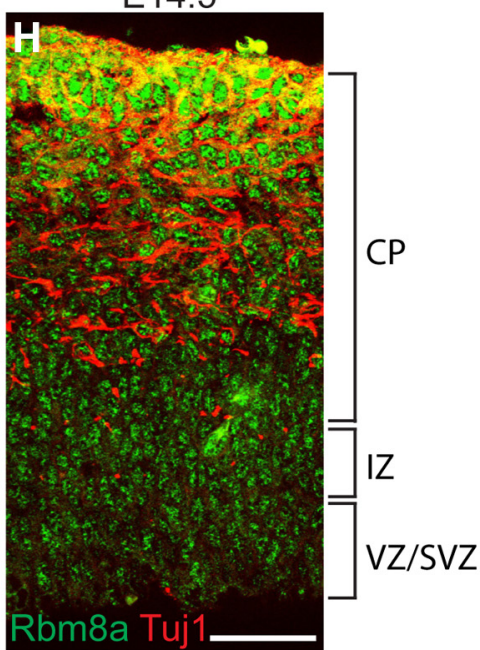

E14.5 Pax6

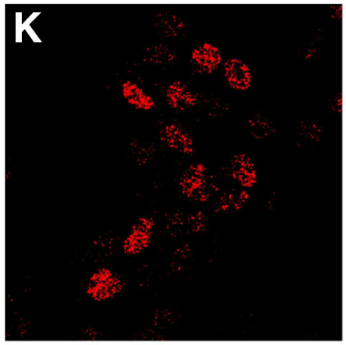

Rbm8a
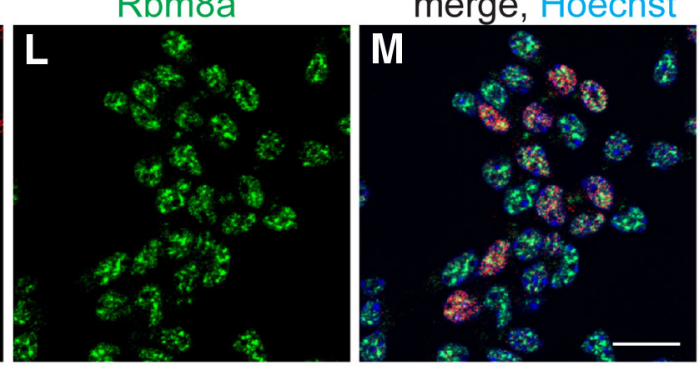

Tuj1,Hoechst

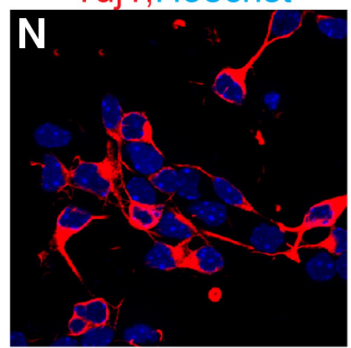

Rbm8a

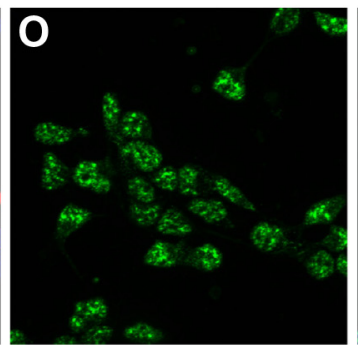

merge

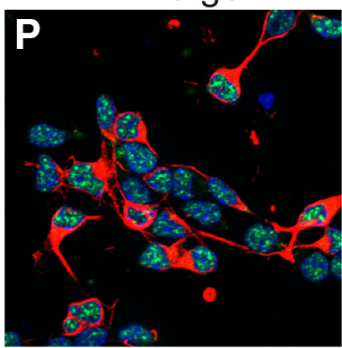


jected $100 \mathrm{ng}$ of RBM8A mRNA into wild-type zebrafish embryos at the one- to two-cell stage. Injected embryos were either fixed at $2 \mathrm{~d}$ post fertilization (dpf) for immunostaining or fixed at $4.5 \mathrm{dpf}$ for head-size measurement; the distance across the convex tips of the eyecups was measured and compared with an age-matched control group from the same clutch. Whole-mount immunostaining with $\mathrm{HuC} / \mathrm{D}$ (postmitotic neurons) was performed for investigating neuronal development and head-size regulation at a cellular level. Embryos were fixed in 4\% PFA overnight and stored in $100 \%$ methanol at $-20^{\circ} \mathrm{C}$. After rehydration in PBS, PFA-fixed embryos were washed in immunofluorescence (IF) buffer $(0.1 \%$ Tween 20 and $1 \%$ BSA in PBS $1 \times)$ for $10 \mathrm{~min}$ at room temperature. The embryos were incubated in the blocking buffer (10\% FBS and $1 \%$ BSA in PBS $1 \times$ ) for $1 \mathrm{~h}$ at room temperature. After two washes in IF buffer for $10 \mathrm{~min}$ each, embryos were incubated in the primary antibody solution, 1:1000 anti-HuC/D (A21271; Life Technologies), in blocking solution overnight at $4^{\circ} \mathrm{C}$. After two washes in IF buffer for $10 \mathrm{~min}$ each, embryos were incubated in the secondary antibody solution, 1:1000 Alexa Fluor goat anti-mouse IgG (A11001; Life Technologies), in blocking solution for $1 \mathrm{~h}$ at room temperature.

\section{Results}

\section{$R b m 8 a$ is expressed in the developing mouse neocortex}

In this study we asked whether the EJC protein, RBM8A, is required for cortical development. To determine the role for $R b m 8 a$ in corticogenesis, we first examined its expression in the developing mouse cerebral cortex. At E10.5, the onset of neurogenesis, we detected Rbm8a mRNA in E10.5 embryonic neocortices using qRT-PCR (Fig. 1A). Relative to E10.5, at both E12.5 and E14.5, Rbm8a levels increased significantly $(p=0.001$ and $p=0.050)$. mRNA in situ hybridization of E14.5 mouse sagittal sections detected robust $R b m 8 a$ expression throughout the embryo, with an enrichment in the ventricular zone (VZ) and subventricular zone (SVZ) of the developing neocortex, where radial glia and IPs reside (Fig. 1B-D; Visel et al., 2004; Englund et al., 2005; Fietz and Huttner, 2011; genepaint.org). The relatively higher Rbm8a RNA levels in the VZ/SVZ layers compared with intermediate zone (IZ)/cortical plate (CP) layers is consistent with $R b m 8 a$ transcriptome data of E14.5 neocortical layers (Ayoub et al., 2011). Given the abundance of Rbm8a in the VZ/SVZ, we assessed RBM8A protein expression at E10.5, E12.5, and E14.5. Immunofluorescence of coronal neocortical sections revealed RBM8A expression throughout the neuroepithelium and

$\leftarrow$

Figure 1. Rbm8a is expressed in the developing cerebral cortex. $\boldsymbol{A}$, Graph depicting relative Rom8a mRNA levels in dorsal telencephalon at three developmental stages. Values were calculated using a standard curve, normalized to Gapdh, and the E10.5 value was set to 1.0. B, C, In situ hybridization for Rbm8a in sagittal E14.5 mouse sections $(\boldsymbol{B})$ and higher magnification view (for region boxed in $\boldsymbol{B}$ ) of the neocortex (C). Note high expression $\left({ }^{*}\right.$ ) in the VZ/SVZ, relative to the CP. Images are from www.genepaint.org (Visel et al., 2004). D, Top, Diagram representation of a coronal section from an E14.5 brain. Box highlights region depicted in diagram schematic at bottom. Bottom, Diagram representation of major cell types examined in this study including radial glial progenitors (red), postmitotic neurons (blue), and intermediate progenitors (green). Radial glia undergo proliferative self-renewal divisions (curved arrow) or neurogenic divisions giving rise to a new radial glia and another daughter cell (orange), which is either a neuron or intermediate progenitor. $\boldsymbol{E}-\boldsymbol{H}$, Images of immunofluorescence staining of Rbm8a (green) in E10.5 (E), E12.5 $(\boldsymbol{F})$, and E14.5 $(\boldsymbol{G}, \boldsymbol{H})$ coronal sections of dorsolateral neocortex. The dotted lines denote the boundary between neocortex and overlying basal epithelium. $\boldsymbol{H}$, Image of the E14.5 coronal section in $\mathbf{G}$ costained with Rbm8a (green) and Tuj1 (red). Note Rbm8a is expressed throughout the neocortex in the VZ/SVZ, IZ, and CP, and is coexpressed with Tuj 1 in the $(P . I, J$, High-magnification images for regions boxed in $\boldsymbol{E}(\boldsymbol{I})$ and $\boldsymbol{F}(\boldsymbol{J})$ showing nuclear enrichment of Rbm8a (green), evidenced by colocalization with Hoechst (blue). Dotted circles denote nuclei. $\boldsymbol{K}-\boldsymbol{P}$, Images of E14.5 primary cell cultures stained for Pax6 (red; $\boldsymbol{K}$ ), TuJ1 (red; $\boldsymbol{N}$ ), and Rbm8a (green; $\boldsymbol{L}, \mathbf{0}$ ) and merged with Hoechst (blue; $\boldsymbol{M}, \boldsymbol{P}$ ). Student's $t$ test, ${ }^{*} p=0.050$, ${ }^{* *} p<0.001, n s, p=0.1074$. Error bars indicate SD, $n=3$ biological replicates each. Scale bars: $\boldsymbol{E}-\boldsymbol{H}, 50 \mu \mathrm{m} ; \boldsymbol{I}, \boldsymbol{J}, 10 \mu \mathrm{m} ; \boldsymbol{K}-\boldsymbol{P}, 20 \mu \mathrm{m}$. neocortex at all three stages (Fig. $1 E-H$ ). We then used both immunofluorescence of E14.5 tissue sections and primary cell culture from E14.5 dorsal cortices to determine whether RBM8A is expressed in progenitors and/or neurons. This experiment revealed Rbm8a expression in both radial glia (Pax6 positive) and neurons (Tuj1 positive; Fig. $1 H-P$ ). In E10.5 and E12.5 tissue sections and in dissociated E14.5 cells, RBM8A localization was primarily nuclear (Fig. $1 I-P$ ). This is consistent with RBM8A's localization in immortalized cells and known function in regulating nucleocytoplasmic mRNA populations, supporting the reliability of this antibody (Bono and Gehring, 2011; Daguenet et al., 2012). These results demonstrate that RBM8A is highly expressed in the developing neocortex, consistent with a potential role in early stages of neurogenesis.

\section{Rbm8a haploinsufficiency causes microcephaly}

To determine the requirement of $R b m 8 a$ in cortical development, we generated a mouse carrying a loxp allele of $R b m 8 a$ (Rbm8 $8 a^{\text {loxp } /+}$; Fig. $2 A$; see Materials and Methods for details). We crossed $R b m 8 a^{\text {loxp } /+}$ mice with Emx1-Cre, which drives Cre expression in neural progenitors of the dorsal telencephalon beginning at E9.5 (Gorski et al., 2002; Chou et al., 2009; Sahara and O'Leary, 2009; cre.jax.org). Genotyping of genomic DNA confirmed two bands of the predicted size in heterozygous Emx1Cre;Rbm $8 a^{\text {loxp/+ }}$ mice but only one band in Emx1-Cre (referred to as control hereafter; Fig. $2 B$ ). Following Cre recombination, the loxp transcript retains exons 1 and 6 but is predicted to undergo nonsense-mediated decay (NMD). qRT-PCR analysis of E10.5 and E12.5 neocortices revealed a 50\% reduction of $\mathrm{Rbm} 8 \mathrm{a}$ mRNA levels in Emx1-Cre;Rbm8a $a^{\text {loxp } /+}$ brains at both stages $(~ p=$ 0.05 , and $p<0.0001$, respectively; Fig. $2 C$ ). The reduced Rbm8a mRNA levels are consistent with haploinsufficiency and suggest the recombined Rbm8a loxp transcript is degraded by NMD. Western blot analysis of E11.5 Emx1-Cre;Rbm $8 a^{\text {loxp/+ }}$ neocortices revealed a $70 \%$ reduction of $\mathrm{Rbm} 8 \mathrm{a}$ protein, as evidenced with two independent polyclonal and monoclonal antibodies ( $p<0.0001$; Fig. $2 D, E$; data not shown). No truncated protein was evident at $3.8 \mathrm{kDa}$, the expected size if a protein product were produced by exons 1 and 6. Given RBM8A's function in translation (Shibuya et al., 2004), reduced RBM8A in Emx1-Cre; $R b m 8 a^{\text {loxp } /+}$ mice may interfere with translation of remaining $R b m 8 a$ transcripts, resulting in a $70 \%$ loss of Rbm8a protein. Consistent with the Western blotting and qRT-PCR results, RBM8A signal was also reduced by immunofluorescence of primary E12.5 cell cultures of Emx1-Cre;Rbm $8 a^{\text {loxp/+ }}$ dorsal neocortices (Fig. $2 F-I$ ). These results indicate that conditional deletion of a single $R b m 8 a$ allele in the developing mouse neocortex induces a $70 \%$ reduction in RBM8A protein levels by E11.5.

Emx1-Cre; $R b m 8 a^{\text {loxp/+ }}$ mice were viable, with normal Mendelian ratios at weaning ( $\chi^{2}$ analysis, $p=0.564, n=22$ mice Emx1-Cre, $n=26$ mice Emx1-Cre;Rbm $\left.8 a^{\text {loxp } /+}\right)$. We examined the cortical size of Emx1-Cre;Rbm8 $a^{\text {loxp } /+}$ mice at P12, by which time embryonic neurogenic events in the cortex are complete. In agreement with an essential role for Rbm8a in corticogenesis, P12 Emx1-Cre; $R b m 8 a^{\text {loxp/+ }}$ brains were significantly microcephalic compared with their littermate controls (Fig. $2 \mathrm{~J}, K$ ). Importantly, Rbm $8 a^{\text {loxp/+ }}$ mouse (control) without Cre exhibited no phenotype and were comparable to C57BL/6J mice (data not shown). Measurement of the dorsal surface area of the cortex showed Emx1-Cre;Rbm8a $a^{\text {loxp } /+}$ brains were $\sim 70 \%$ smaller than control $(p<0.0001$; Fig. $2 L)$. These results demonstrate that haploinsufficiency for $R b m 8 a$ causes severe microcephaly. 
A

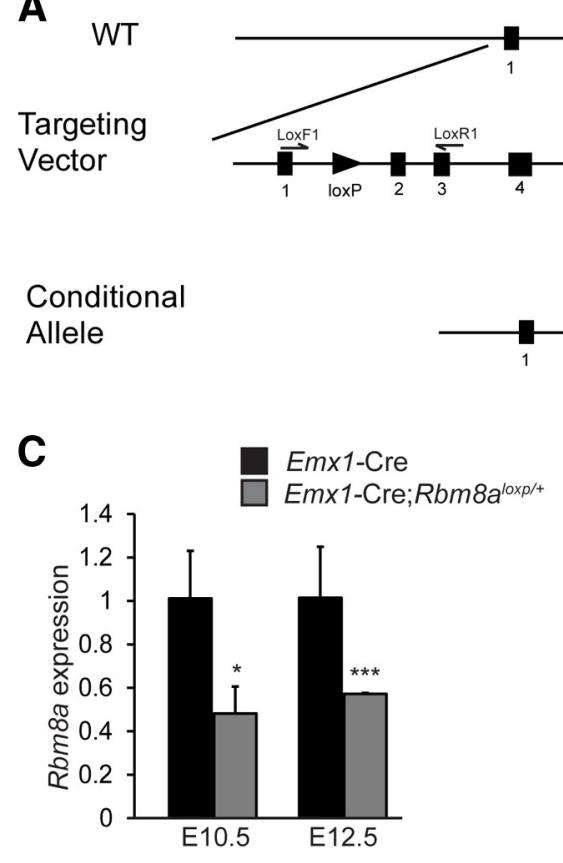

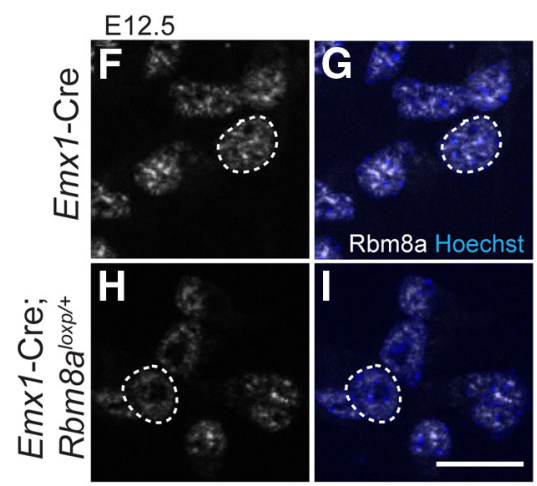
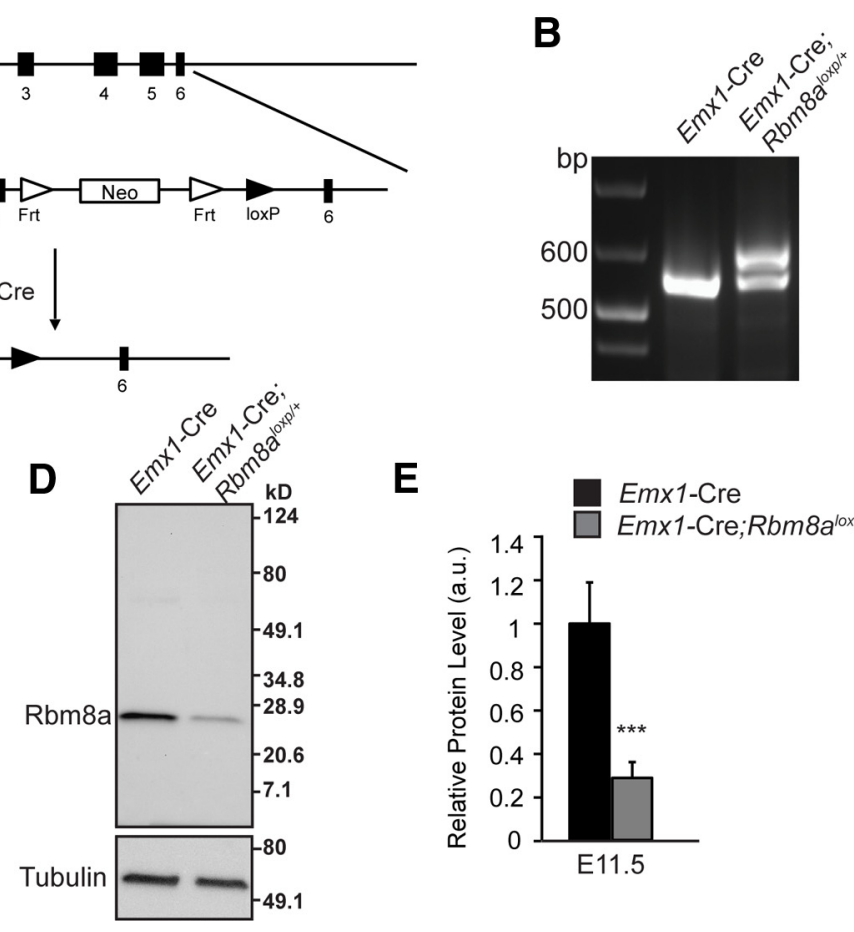

$\mathbf{E}$
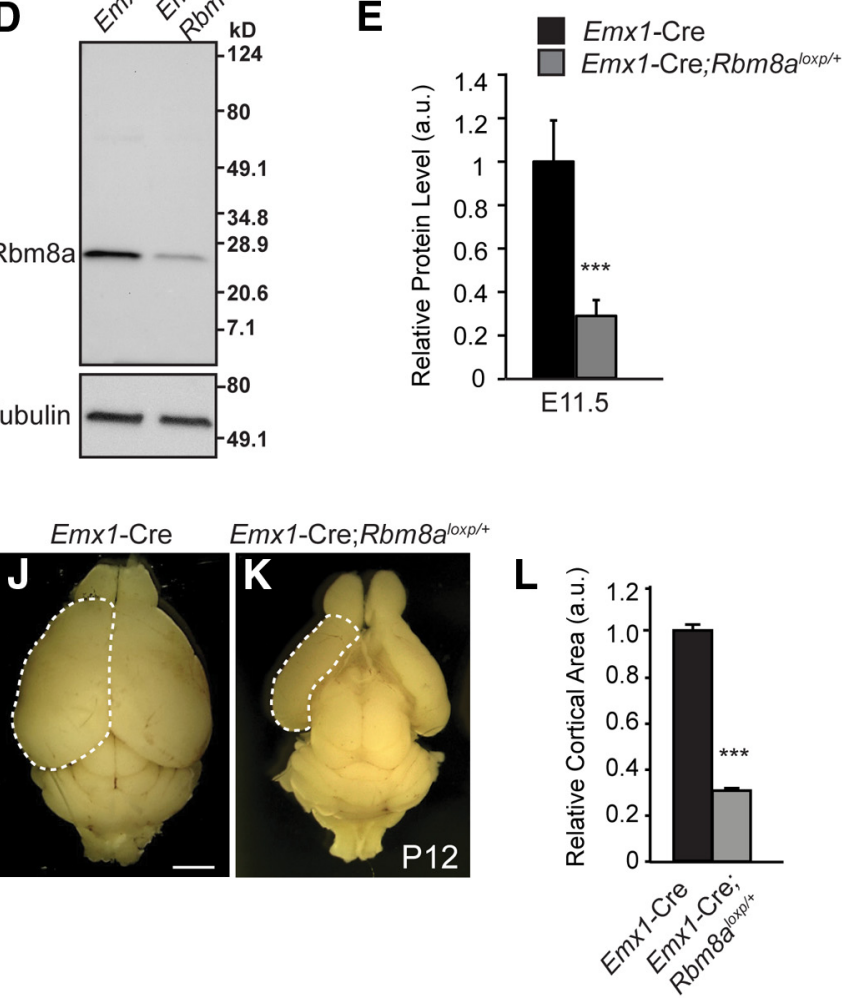

Figure 2. Conditional Rbm8a haploinsufficiency in the dorsal telencephalon causes severe microcephaly. $\boldsymbol{A}$, Top, Schematic of wild-type genomic locus of Rbm8a with six exons (black boxes) and introns (lines, not to scale). Middle, Targeted allele with two loxp sites (black arrowheads), neo cassette, and two FRT sites. Primers for genotyping are shown as arrows (LoxF1, LoxR1). Bottom, Conditional allele following Cre-mediated recombination. $\boldsymbol{B}$, Representative PCR genotyping result from Emx 1 -Cre (control) and Emx 1 -Cre; Rbm8a $a^{\text {loxp/+ }}$ mice. Note a single band ( 550 bp) in control and two bands (550 and $584 \mathrm{bp}$ ) in Emx1-Cre;Rbm8a $a^{\text {oxp } /+}$. C, qRT-PCR quantification of Rbm8a mRNA levels in E10.5 neocortices and E12.5 dorsal neocortices of indicated genotypes, following normalization using Gapdh. Rbm8a mRNA levels of Emx1-Cre samples were set to 1.0. D, Representative Western blot of E11.5 dorsal neocortical lysates probed for anti-Rbm8a or anti- $\alpha$-tubulin. Note a single band is evident in $E m \times 1-C r e ; R b m 8 a^{\text {loxp } /+}$. Protein samples were run to the bottom of the gel without running off to allow transfer of all molecular weights. $\boldsymbol{E}$, Quantification of Rbm8a protein levels by densitometry of Western blots, following normalization with $\alpha$-tubulin for loading. $\boldsymbol{F}$-I, Images of primary E12.5 cortical cells from Emx 1 -Cre $(\boldsymbol{F}, \mathbf{G})$ or Emx1-Cre;Rbm8a ${ }^{\text {loxp } /+}$ $(\boldsymbol{H}, \boldsymbol{I})$ dorsal neocortices, stained for RBM8A (white) or Hoechst (blue). Images were captured at identical exposure settings. Note lower immunofluorescence Rbm8a staining in $R b m 8 a$ mutant cells. $\boldsymbol{J}, \boldsymbol{K}$, Images of whole-mount brains at P12 from Emx1-Cre $(\boldsymbol{J})$ and Emx1-Cre;Rbm8a ${ }^{\text {loxp } /+}(\boldsymbol{K})$ mice. Dotted circles denote dorsal cortex. $\boldsymbol{L}, \mathrm{Q}$ uantification of relative cortical area in P12 brains of indicated genotypes. Student's $t$ test, ${ }^{*} p \leq 0.05,{ }^{* * *} p<0.0001$. Error bars indicate SD, $n=3$ biological replicates each. Scale bars: $\boldsymbol{F}-\mathbf{I}, 20 \mu \mathrm{m} ; \boldsymbol{J}, \boldsymbol{K}, 2 \mathrm{~mm}$.

To determine the onset of microcephaly in Rbm8a haploinsufficient mice, we next examined the cortical thickness of embryonic brains using coronal sections. At E11.5, Emx1-Cre; Rbm $8 a^{\text {loxp } /+}$ and control brains exhibited comparable cortical thickness ( $p=0.801$; Fig. $3 A, B, I)$. However, by E12.5, Emx1Cre;Rbm8a $a^{\text {loxp/+ }}$ cortices were $21 \%$ thinner than control $(p=$ 0.005; Fig. 3C, D, I). By E13.5, Emx1-Cre; Rbm8a $a^{\text {loxp/+ }}$ dorsal cortices were $50 \%$ thinner than control, and this was evident in both dorsal and more lateral cortical regions $(p<0.0001$, both; Fig. $3 E-I)$. By E14.5, Emx1-Cre;Rbm8a ${ }^{\text {loxp } /+}$ brains were markedly microcephalic, and coronal sections revealed the ventricle and dorsal telencephalon were severely reduced (Fig. 3J-O). Staining for radial glia, IPs, and neurons within the lateral region adjacent to the ganglionic eminence revealed the presence of these cell populations in the remaining neocortex (Fig. $3 P-U$ ). These analyses demonstrate that in Emx1-Cre;Rbm $8 a^{\text {loxp/+ }}$ mice, the microcephaly arises during embryogenesis between E11.5 and E12.5, a period corresponding to progenitor proliferation and the onset of neuron production (Greig et al., 2013).

\section{$R b m 8 a$ is required for proper number of radial glia and} intermediate progenitors

Given the timing of microcephaly onset, the $R b m 8 a$ expression pattern, and the correlation between progenitor dysfunction and microcephaly, we next assessed progenitors in more detail in Emx1-Cre;Rbm8 $a^{\text {loxp } /+}$ cortices. We quantified radial glia num- 

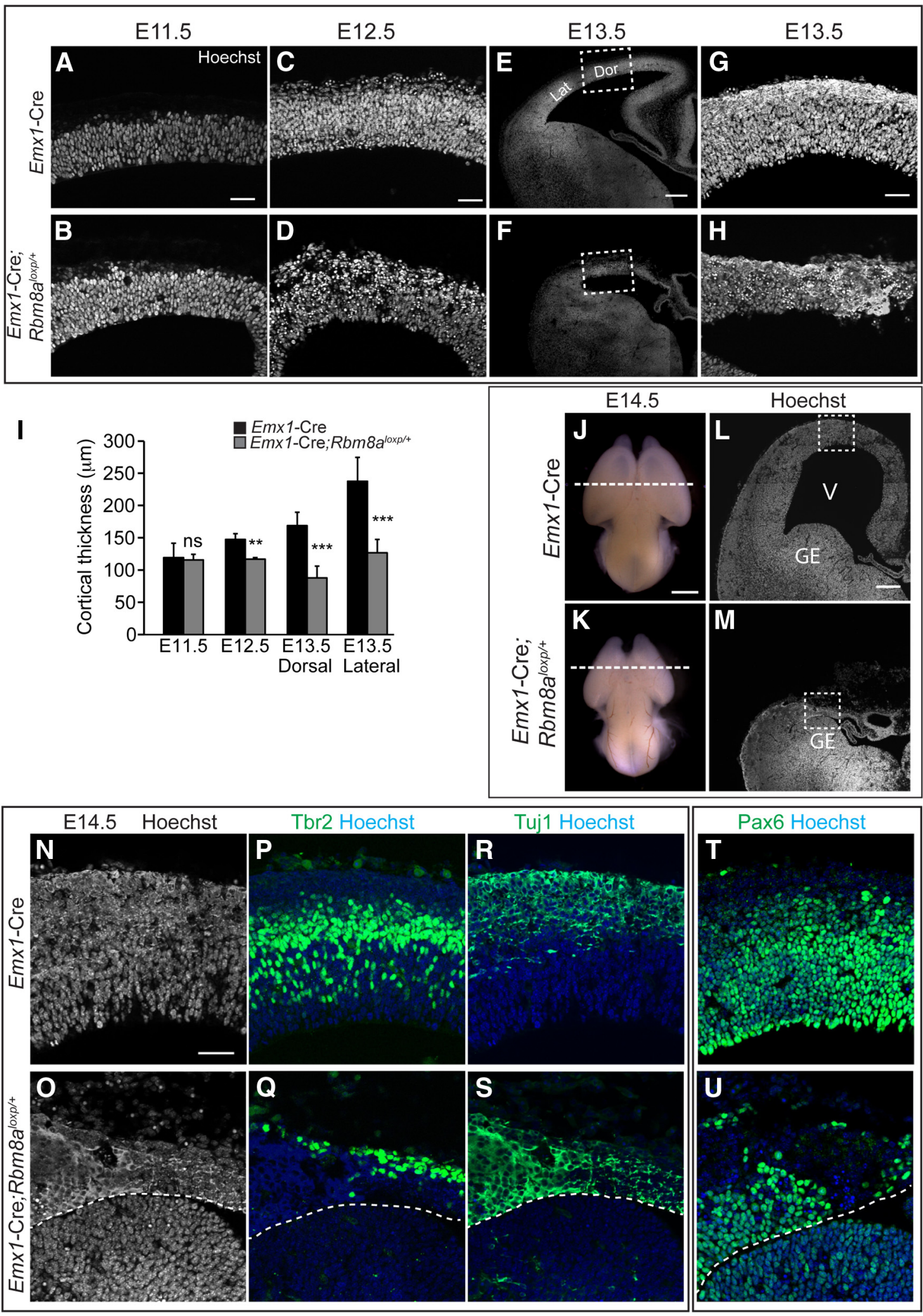

Figure 3. Rbm8a haploinsufficiency results in a thinner neocortex. $\boldsymbol{A}-\boldsymbol{H}$, Cortical sections from Emx1-Cre $(\boldsymbol{A}, \boldsymbol{C}, \boldsymbol{E}, \boldsymbol{G})$ and $E m \times 1-C r e ; R b m 8 a^{\text {loxp } /+}(\boldsymbol{B}, \boldsymbol{D}, \boldsymbol{F}, \boldsymbol{H})$ brains from E11.5 $(\boldsymbol{A}, \boldsymbol{B}), \mathrm{E} 12.5(\boldsymbol{C}, \boldsymbol{D})$, and $\mathbf{E 1 3 . 5}(\boldsymbol{E}-\boldsymbol{H})$ embryos stained for Hoechst. Images in $\boldsymbol{A}-\boldsymbol{D}$ were from lateral regions at medial rostrocaudal positions. $\boldsymbol{G}, \boldsymbol{H}$, High-magnification images of regions indicated in $\boldsymbol{E}$ and $\boldsymbol{F}$. $\boldsymbol{I}$, Quantification of cortical thickness in $E m \times 1$-Cre and Emx1-Cre; Rbm8 $\mathrm{a}^{\text {loxp/+ }}$ dorsal neocortices of indicated ages. Note measurements were made at both dorsal (dor) and more lateral (lat) regions as indicated in $\boldsymbol{E}$. J, $\boldsymbol{K}$, Whole-mount E14.5 brains from indicated genotypes. $L, M$, Hoechst-stained coronal neocortical sections from indicated genotypes at rostrocaudal regions indicated by dotted lines in $\boldsymbol{J}$ and $\boldsymbol{K} . \boldsymbol{N}-\boldsymbol{U}$, High-magnification images of coronal neocortical sections from regions indicated in $\boldsymbol{L}$ and $\boldsymbol{M}$. Images were stained for Hoechst (white or blue), Tbr2 (green; $\boldsymbol{P}, \boldsymbol{Q}$ ), Tuj 1 (green; $\boldsymbol{R}, \boldsymbol{S}$ ), and Pax6 (green; $\boldsymbol{T}, \boldsymbol{U}$ ). Images in $\boldsymbol{N}, \boldsymbol{P}, \boldsymbol{R}$, and $\mathbf{O}, \boldsymbol{Q}, \boldsymbol{S}$ are from identical sections, and images in $\boldsymbol{T}$ and $\boldsymbol{U}$ are from different sections. Note the markedly reduced ventricle and dorsal telencephalon in Emx1-Cre;Rbm8a ${ }^{\text {loxp/+ }}$. V, ventricle; GE, ganglionic eminence. All images show sections from medial rostrocaudal positions. Student's t test, ns, $p>0.80,{ }^{* *} p<0.01,{ }^{* * *} p<0.0001$. Error bars indicate $S D, n=3$ biological replicates each. Scale bars: $A-D, G, H, N-U, 50 \mu \mathrm{m} ; \boldsymbol{E}, \boldsymbol{F}, \mathbf{L}, \boldsymbol{M}, 200 \mu \mathrm{m} ; \boldsymbol{J}, \boldsymbol{K}, 1 \mathrm{~mm}$. 

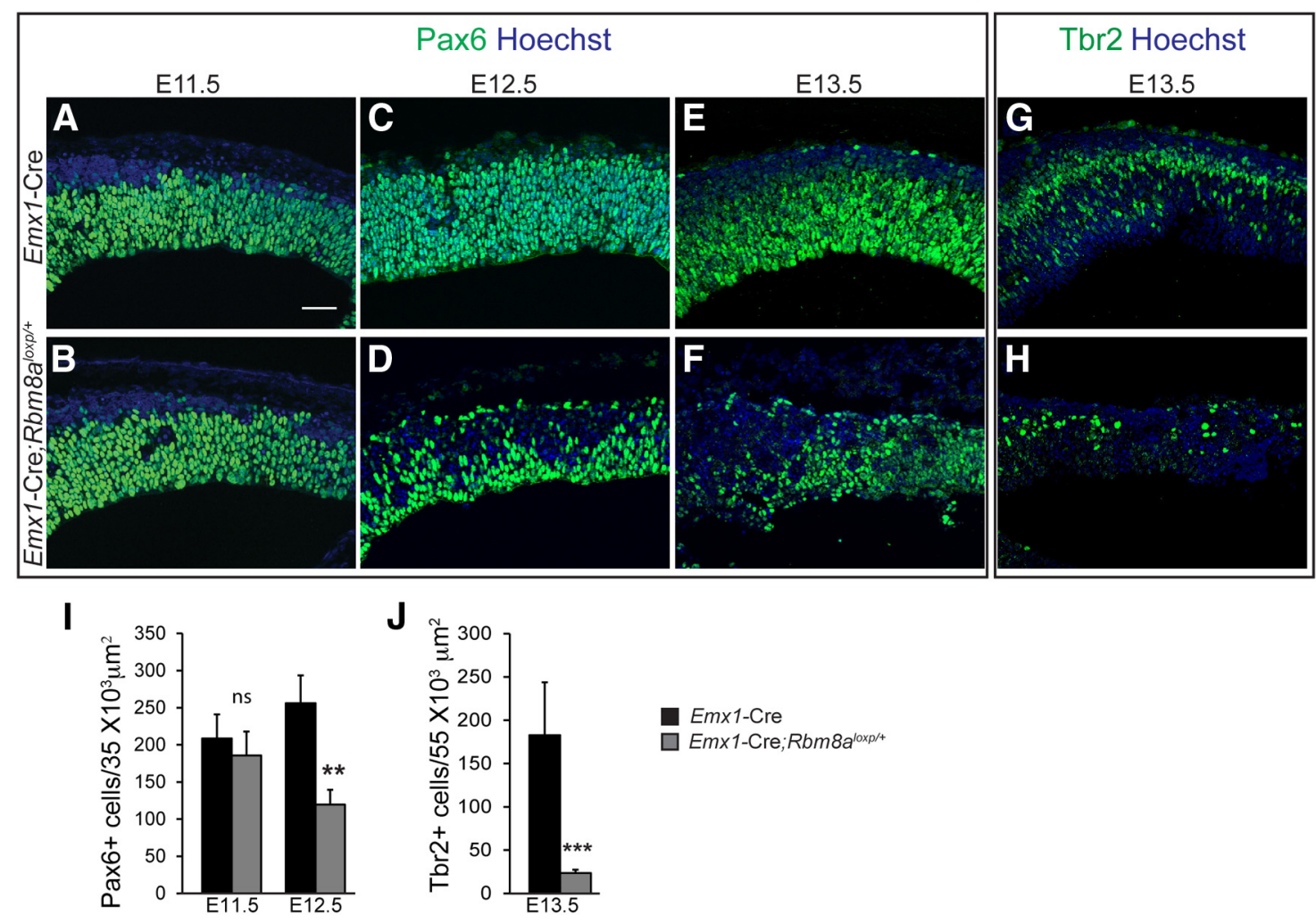

Figure 4. Rom8a is required for proper number of radial glia and intermediate progenitors. $\boldsymbol{A}-\boldsymbol{H}$, Coronal sections from $E m \times 1-C r e ~(\boldsymbol{A}, \boldsymbol{C}, \boldsymbol{E}, \boldsymbol{G})$ and $E m \times 1-C r e ; R b m 8 a^{10 x p /+}(\boldsymbol{B}, \boldsymbol{D}, \boldsymbol{F}, \boldsymbol{H})$ brains from E11.5 $(\boldsymbol{A}, \boldsymbol{B}), \mathrm{E} 12.5(\boldsymbol{C}, \boldsymbol{D})$, and E13.5 $(\boldsymbol{E}-\boldsymbol{H})$ embryos, and stained for Hoechst (blue; $\boldsymbol{A}-\boldsymbol{H}$ ), Pax6 (green; $\boldsymbol{A}-\boldsymbol{F}$ ), and Tbr2 (green; $\boldsymbol{G}, \boldsymbol{H})$. $\boldsymbol{I}$, Pax6-positive cells within a $35 \times 10^{3} \mu \mathrm{m}^{2}$ field of view in cortices of indicated genotypes and ages. $J$, Tbr2-positive cells within a $55 \times 10^{3} \mu \mathrm{m}^{2}$ field of view in cortices of indicated genotypes at E13.5. All images were taken from dorsolateral regions at the medial rostrocaudal position represented in Figure $1 D$. Student's t test, ${ }^{* *} p<0.01,{ }^{* * *} p<0.0001, \mathrm{~ns}, p=0.435$. Error bars indicate SD, $n=3$ biological replicates each. Scale bars: $\boldsymbol{A}-\boldsymbol{H}, 50 \mu \mathrm{m}$.

ber (Pax6-positive cells) in mutant and control brains. At E11.5, we observed similar densities of radial glia in control and Emx1Cre;Rbm8a $a^{\text {loxp/+}}$ brains ( $p=0.435$; Fig. $4 A, B, I$ ), which is consistent with the normal dorsal cortical thickness at E11.5. Similarly, Pax6 mRNA levels in E10.5 Emx1-Cre;Rbm8 $a^{\text {loxp } /+}$ and control brains were also similar ( $100 \pm 27.69 \%$ vs $114 \pm 5.05 \%$, $p=0.618$ ). However, by E12.5 we noted a significant $54 \%$ reduction in the density of radial glia in Emx1-Cre;Rbm8 $a^{\text {loxp /+ }}$ brains compared with control ( $p=0.002$; Fig. $4 C, D, I$ ). At E13.5, the remaining radial glia in the neocortex appeared disorganized (Fig. $4 E, F)$. These results indicate Pax6-positive radial glial cells are initially produced in $R b m 8 a$-haploinsufficient E11.5 brains, but are decreased significantly in number within a day of development. Hence the reduced cortical thickness of E12.5 mutants may be due in part to fewer radial glia. As radial glia produce IPs, we assessed the impact of radial glia depletion upon IP number. At E13.5 we observed an $87 \%$ reduction in the density of Tbr2positive IPs in Emx1-Cre; Rbm8a ${ }^{\text {loxp/+ }}$ cortices ( $p=0.0001$; Fig. $4 G, H, J)$. These analyses indicate that $R b m 8 a$ regulates the number of both radial glia and intermediate progenitors in the developing neocortex. As both populations produce excitatory neurons, ultimately this would be predicted to have a severe impact on neuronal output.

\section{Rbm8a haploinsufficient embryonic neocortices contain ectopic neurons}

Having established $R b m 8 a$ is required for the proper number of radial glia and IPs, we next examined the impact of $R b m 8 a$ depletion upon neurons. Loss of radial glia can sometimes be explained by precocious production of neurons at the expense of progeni- tors, as seen in many microcephaly mutants, including $\mathrm{Magoh}^{+/-}$ (Yingling et al., 2008; Silver et al., 2010; Xie et al., 2013; Insolera et al., 2014). To evaluate neurons, we first performed immunofluorescence of coronal sections using the neuronal marker Tuj1, which labels immature neurons of the cortical plate. At E11.5 we observed no obvious difference in the relative distribution of Tuj1-positive neurons of Emx1-Cre;Rbm8a $a^{\text {loxp/+ }}$ and control brains (Fig. $5 A, B$ ). However, by E12.5 the layer of Tuj1-positive neurons was strikingly thicker in Emx1-Cre; $R b m 8 a^{\text {loxp/+ }}$ cortices compared with control (Fig. 5C,D). This phenotype persisted at E13.5, at which stage Tuj1-positive cells were detectable throughout the thickness of the dorsal Emxl-Cre;Rbm8 $a^{\text {loxp } /+}$ neocortex (Fig. $5 E, F$ ). These results demonstrate that loss of Rbm8a leads to aberrant distribution of postmitotic neurons.

Altered neuron distribution could be caused by defective neuronal migration and/or increased neuron number. To further ascertain the cause, we quantified deep-layer neurons in E12.5 cortices using Tbr1 immunostaining (Fig. 5G-I). This analysis revealed a significant increase in Tbr1-positive neurons in the Emx1-Cre;Rbm8 $a^{\text {loxp/+ }}$ neocortex compared with control $(p=$ 0.001 ). We also used E12.5 dissociated primary cultures to quantify neurons and progenitors (Fig. $5 J-L$ ). The overall distribution of cell types was different between control and Emx1-Cre; $R b m 8 a^{\text {loxp/+ }}(p<0.0001)$. Compared with control, Rbm8a haploinsufficiency induced a 2.7-fold increase in neurons $(p=0.007$; Tuj1+ only; Fig. 5L). Concomitantly, Pax6-positive radial glia were reduced by 1.5 -fold in Emx1-Cre; $R b m 8 a^{\text {loxp } /+}$ cortices $(p=$ 0.002; Pax6+ only; Fig. 5L). These differences were sustained at E13.5, when there was a 2.5-fold increase in neurons and a twofold decrease in radial glia ( $p=0.003$ and $p=0.036$, respectively; 
data not shown). These results are consistent with the $50 \%$ loss of radial glia quantified in E12.5 Emx1-Cre; Rbm8a $a^{\text {loxp } /+}$ brain sections. Moreover, these fold changes are consistent with the presence of more neurons in Rbm8adeficient cortices.

$R b m 8 a$ haploinsufficiency impacts the balance between proliferation and differentiation of neural progenitors As $R b m 8 a$ haploinsufficiency altered the number of neurons and progenitors, we posited this could be due to premature neuronal differentiation of radial glia. At E11.5 radial glial cells undergo selfrenewing divisions to produce new progenitors, and they also begin to produce neurons via neurogenic divisions. If loss of $R b m 8 a$ triggers premature neuronal differentiation, we expected that in $R b m 8 a$ mutant brains, a higher proportion of progenitors would exit the cell cycle. To test this possibility, we quantified cell-cycle exit of E11.5 progenitors using dissociated cells. Progenitors were pulsed with EdU for $30 \mathrm{~min}$ to label S-phase and analyzed $24 \mathrm{~h}$ later. We quantified both cycling progenitors $(\mathrm{EdU}+\mathrm{Ki} 67+)$ and cells that had exited the cell cycle (EdU +Ki67-; Fig. 6A-F). Compared with control, Emx1Cre;Rbm8aloxp/+ showed a significantly lower fraction of EdU + Ki67+ cycling progenitors $(p=0.015$; Fig. $6 G)$. This indicates that $R b m 8 a$ deficiency causes a higher fraction of progenitors to exit the cell cycle, which is consistent with fewer radial glia observed in E12.5 cultures and sections. We also observed a significantly higher fraction of EdU+Tuj1+ cells in Emx1-Cre; $R b m 8 a^{\text {loxp } /+}$ progenitors $(p=0.002$; Fig. $6 H$ ). This result indicates that the increased cell-cycle exit is associated with more neurons, consistent with neuronal analyses of cultures and tissue sections. These data show that $R b m 8 a$ functions in radial glia to prevent premature exit from the cell cycle.

Given the expression pattern of Rbm8a and its function in regulating radial glia number, we next asked whether proliferation was impacted in $R b m 8 a$ haploinsufficient brains. We previously showed that RBM8A knockdown in human cell culture induces an abnormally high fraction of $\mathrm{G}_{2} / \mathrm{M}$ cells (Silver et al., 2010); therefore, we assessed whether Rbm8a haploinsufficiency affects $G_{2} / M$ phases of E1 1.5 cortical progenitors by performing phospho-histone3 ( $\mathrm{PH} 3$ ) staining. Consistent with prior published cell-culture data (Silver et al., 2010), we observed a significant increase in PH3 staining in E11.5 Emx1Cre; $R b m 8 a^{\text {loxp } /+}$ brains, compared with control $(p=0.042$; Fig. $6 I-K)$. Increased PH3 staining has also been seen in other microcephaly mutants (Feng and Walsh, 2004; Yingling et al., 2008;
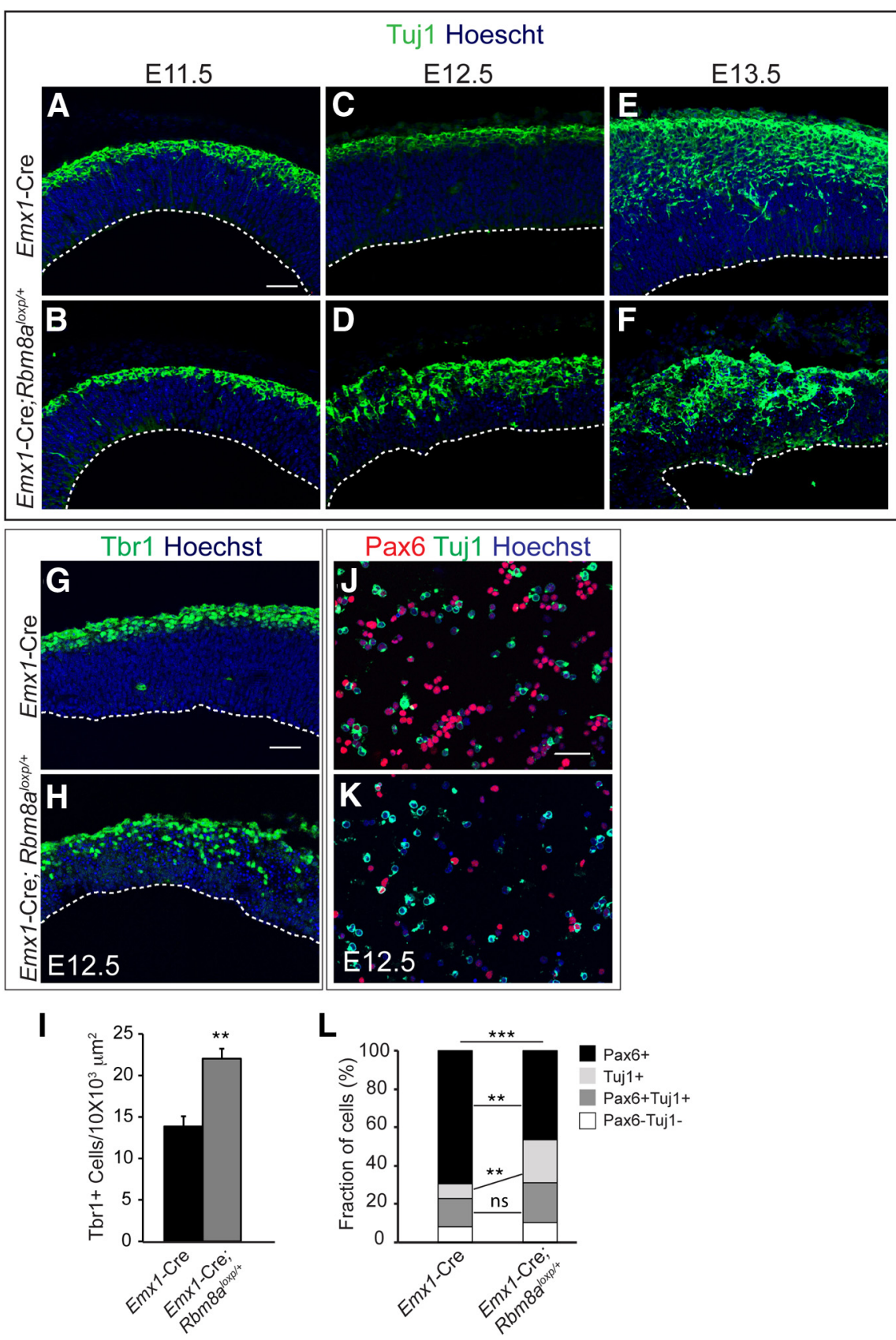

Figure 5. Rbma8a-deficient brains contain ectopic neurons. $\boldsymbol{A}-\boldsymbol{F}$, Coronal sections from Emx1-Cre $(\boldsymbol{A}, \boldsymbol{C}, \boldsymbol{E})$ and $E m \times 1-C r e$; Rbm8a $a^{\text {loxp/+ }}(\boldsymbol{B}, \boldsymbol{D}, \boldsymbol{F})$ brains from E11.5 $(\boldsymbol{A}, \boldsymbol{B}), \mathrm{E} 12.5(\boldsymbol{C}, \boldsymbol{D})$, and E13.5 $(\boldsymbol{E}, \boldsymbol{F})$ embryos, and stained for Hoechst (blue) and Tuj1 (green). Note the expanded domain of Tuj1-positive cells in E12.5 and E13.5 Rbm8a-deficient brains. $\boldsymbol{G}, \boldsymbol{H}$, E12.5 coronal sections from Emx1-Cre (G) and Emx1-Cre;Rbm8a $a^{\text {loxp/+ }}(\boldsymbol{H})$ brains stained for Hoechst (blue) and Tbr1 (green). Note the disorganized distribution of Tbr1-positive neurons in the Rbm8a-deficient brains. $I$, Tbr1-positive cells within a $10 \times 10^{3} \mu \mathrm{m}^{2}$ cortical area of indicated genotypes at E12.5.J, $\boldsymbol{K}$, Primary dissociated cells from E12.5 dorsal neocortices from indicated genotypes and stained for Pax6 (red), Tuj1 (green), and Hoechst (blue). $L$, Bar graph depicting fraction of positive cells for indicated markers. All images were taken from dorsolateral regions at the medial rostrocaudal position represented in Figure $1 D$. $I$, Student's $t$ test. $L, \chi^{2}$ analysis followed by post hoc two-tailed Student'st test, ${ }^{* *} p<0.007,{ }^{* * *} p<0.0001, n s, p>0.16$. Errorbars indicate SD, $n=3$ biological replicates each. Scale bars: $\boldsymbol{A}-\boldsymbol{K}, 50 \mu \mathrm{m}$.

Marthiens et al., 2013; Chen et al., 2014). These data indicate that in E11.5 Rbm8a haploinsufficient brains, progenitor proliferation is altered before any significant change in radial glia number or cortical thickness.

Rbm8a haploinsufficiency causes widespread apoptosis $R b m 8 a$ could influence neuron number in two ways: by producing neurons at the expense of progenitors or by preferential apo- 

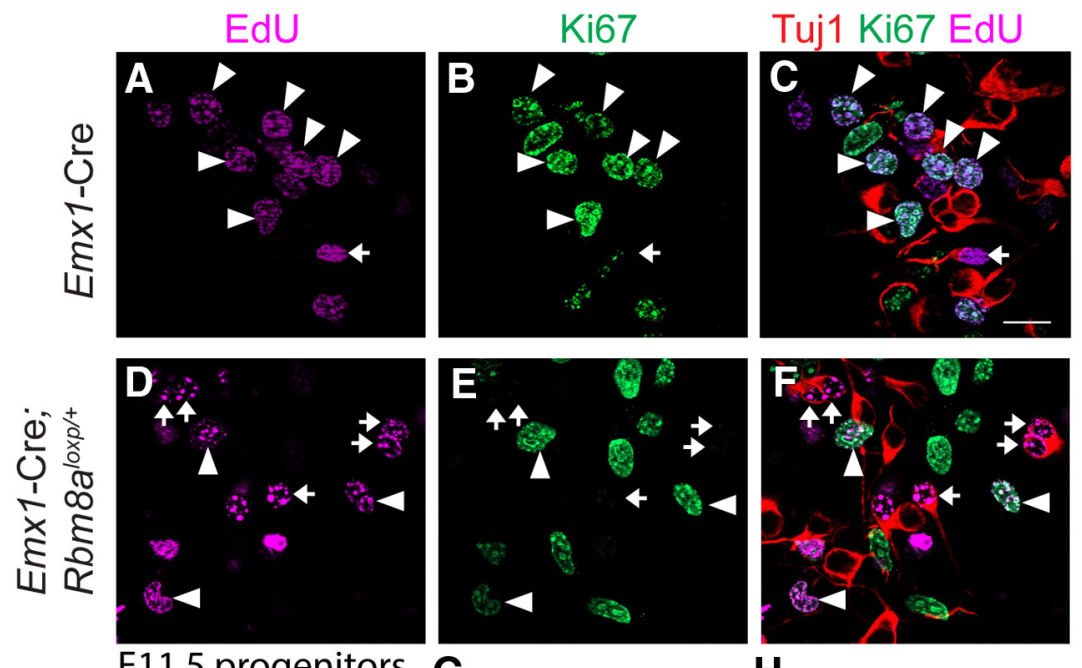

E11.5 progenitors

H
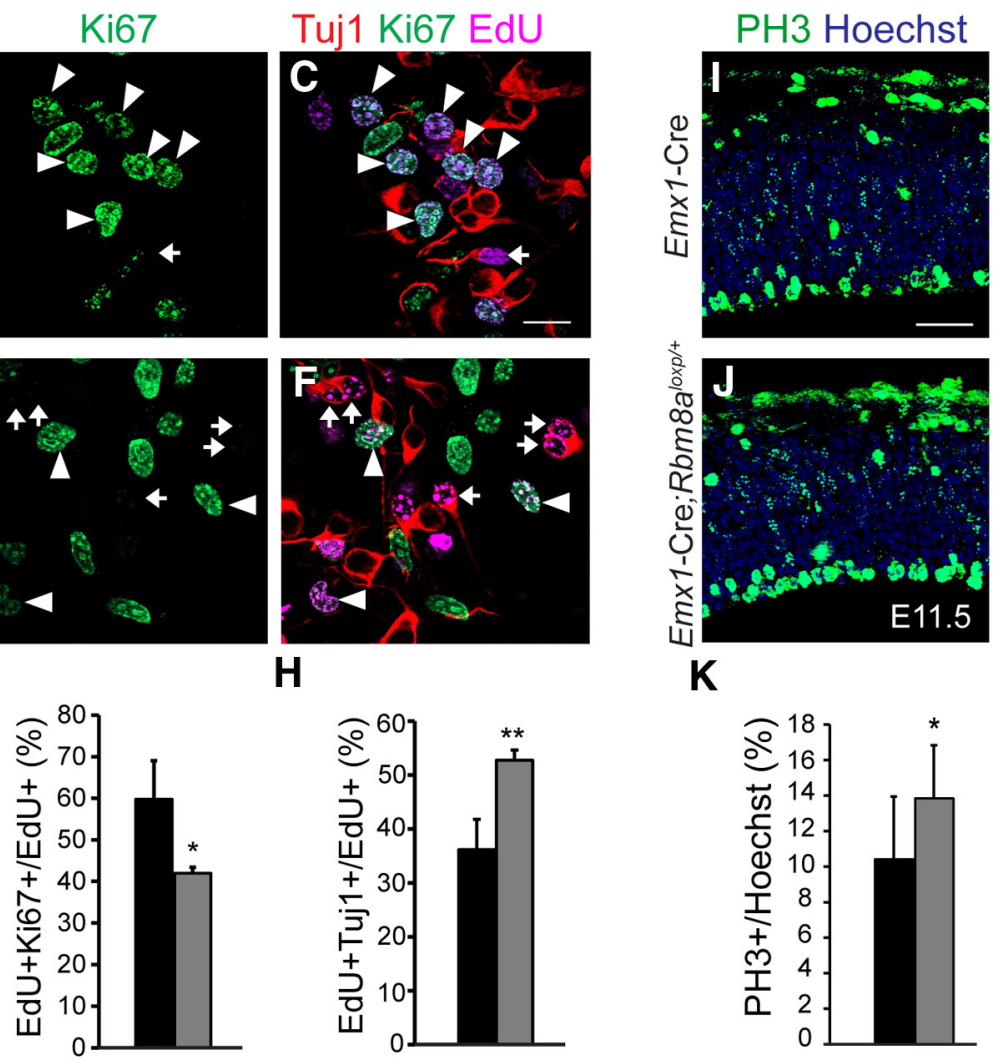

Figure 6. Rbm8a regulates cell-cycle exit of neural progenitors. $\boldsymbol{A}-\boldsymbol{F}$, Primary dissociated cells from $E 11.5$ dorsal neocortices from $E m \times 1-C r e ~(\boldsymbol{A}-\boldsymbol{C})$ or $E m \times 1-\left(\mathrm{Cre} ; R b m 8 a^{\text {loxp } /+}(\boldsymbol{D}-\boldsymbol{F})\right.$ were cultured for $1 \mathrm{~d}$ following a $30 \mathrm{~min}$ EdU pulse and then stained for Tuj1 (red), Ki67 (green), and EdU (purple). Arrowheads, EdU + Ki67 + cells; arrows, EdU + Tuj1 + cells. G, H, Percentages of all EdU-positive

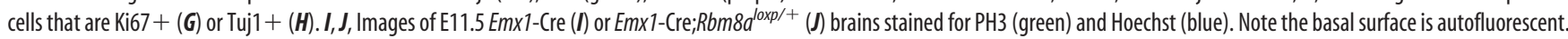
$\boldsymbol{K}$, Graph depicting percentage of PH3-positive cells for indicated genotypes. Student's $t$ test, ${ }^{*} p<0.05,{ }^{* *} p<0.01$. Error bars indicate SD, $n=3-6$ cultures or brains from independent biological replicates each genotype. Scale bars: $\boldsymbol{A}-\boldsymbol{F}, 20 \mu \mathrm{m} ; \boldsymbol{I}, \boldsymbol{J}, 50 \mu \mathrm{m}$.

ptosis of progenitors leading to disproportionately higher neuronal fractions. Based on the cell-cycle exit analysis we favored the former mechanism; however, to address the second possibility we assessed apoptosis in Rbm8a haploinsufficient brains. To examine apoptosis, we performed immunofluorescence for cleaved-caspase3 (CC3) and TUNEL, mid- and latestage apoptosis markers, respectively. At E11.5, there was a slight increase in apoptosis of Emx1-Cre;Rbm8a $a^{\text {loxp/+ }}$ compared with control (Fig. $7 A, B$ ). This mild phenotype was consistent with normal cortical thickness and progenitor number observed at this age. Beginning at E12.5 much more extensive apoptosis was observed only in Emx 1-Cre; Rbm8a $a^{\text {loxp } /+}$ dorsal cortices (Fig. 7C$G)$. Apoptosis was evident throughout the thickness of the neocortex, and was especially high in basal layers (CP and subplate), where neurons reside following migration.

Having established that extensive apoptosis occurs at E12.5 coincident with progenitor loss, we next examined which populations of cells undergo apoptosis. Based on the distribution of apoptotic cells, we posited that neurons undergo apoptosis. Indeed, colocalization of CC 3 and Tuj1 revealed neuronal apoptosis in Emx1-Cre;Rbm8a $a^{\text {loxp } /+}$ mutants (Fig. $7 \mathrm{H}-\mathrm{K}$ ). We also detected CC $3+$ Pax6 + cells in E12.5 brains, demonstrating some radial glial cells are eliminated by apoptosis (Fig. $7 \mathrm{~L}-\mathrm{O}$ ). If higher neuronal fractions were explained by preferential progenitor apoptosis, we predicted to observe more dying radial glial cells than dying neurons. However, radial glia apoptosis was less extensive than neuronal apoptosis, with $\sim 7 \%$ of all Pax6 + radial glia undergoing apoptosis, compared with $21 \%$ of all Tuj $1+$ neurons $(p=0.005)$. One technical explanation for this result is that Pax6 is a nuclear marker and its epitope could be lost in apoptotic cells. However, the high abundance of apoptotic cells in basal layers of the neocortex, together with this colocalization analysis, indicates apoptosis is not skewed toward radial glia. Our developmental analyses of Rbma8a haploinsufficient embryos indicate proliferation and cell-cycle exit defects precede both altered cell populations and apoptosis. This suggests Rbm8a impacts radial glia and neuron number by first influencing progenitor proliferation. In the mutant, aberrant populations are then eliminated by apoptosis.

\section{Rbm8a haploinsufficiency impacts neuronal layers}

Having observed both proliferation and apoptosis defects early in neurogenesis, we next examined the impact of $R b m 8 a$ depletion upon neuronal layers at the end of neurogenesis. Specifically we asked whether there were differences in upper versus lower layers of P0 Rbm8a haploinsufficient brains. Analysis of P0 brains revealed a marked microcephaly in Emxl-Cre; $R b m 8 a^{l o x p /+}$ mutants, consistent with analysis at other stages (Fig. 8A,B). Remarkably, most of the neocortex was missing in Rbm8a haploinsufficient brains, as evidenced by coronal tissue sections (Fig. $8 C, D)$. To determine which neuronal populations were present in remaining neocortical tissue, we performed immunofluorescence of medial sections for Cux1 (layers II/III), Foxp1 (layers III-V), and Tbrl (layer VI; Fig. $8 E-J$ ). Strikingly, Rbm8adeficient brains had a significant dearth of both Cuxl and Foxp1positive neurons, compared with control $(p<0.0001$ each; Fig. 

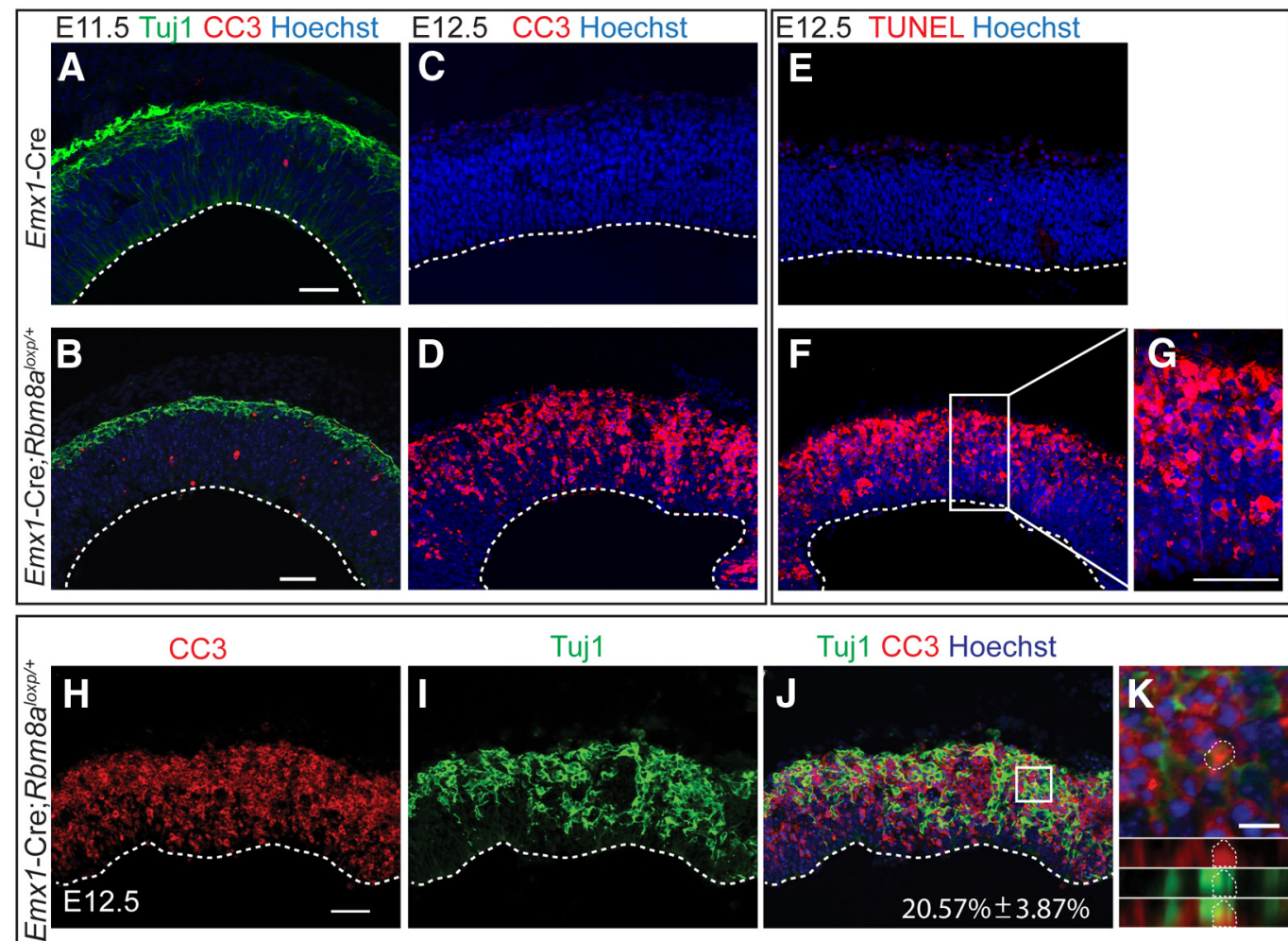

Tuj1 CC3 Hoechst
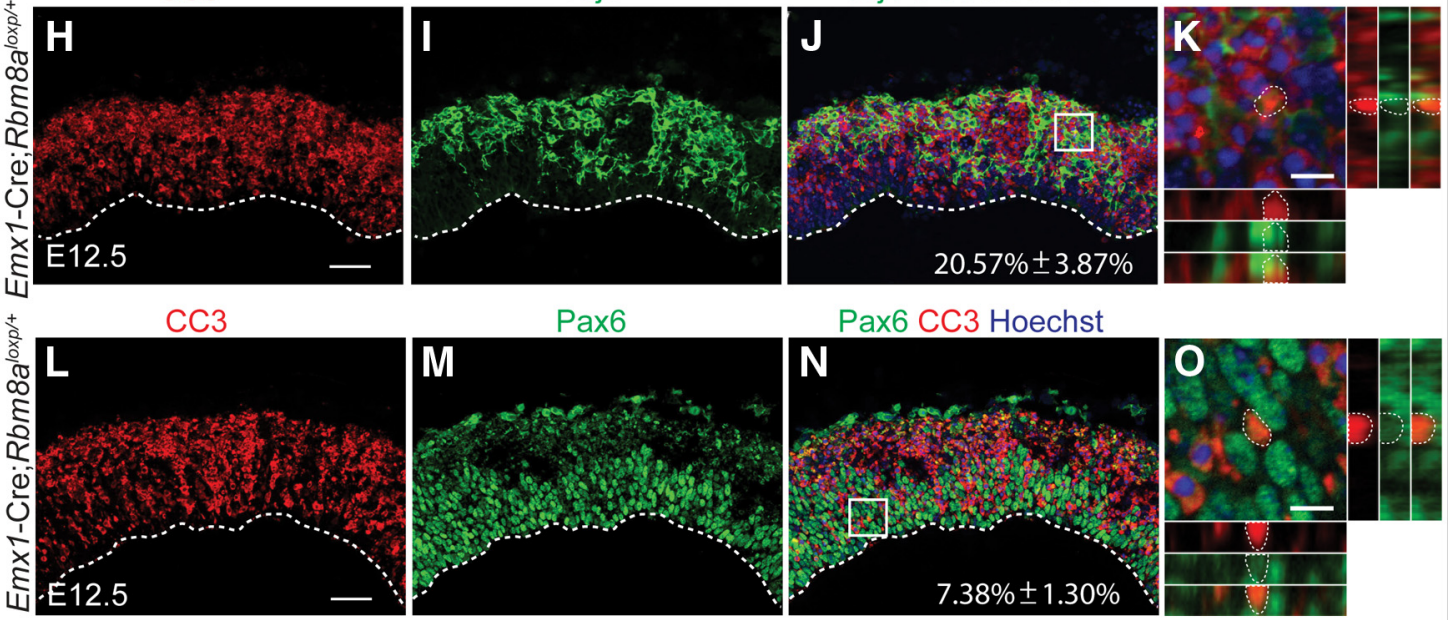

Pax6 CC3 Hoechst
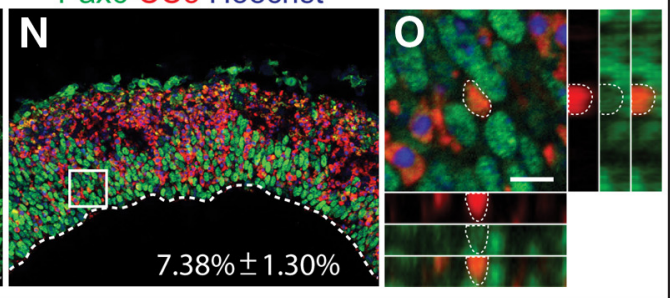

Figure 7. Rbm8a deficiency induces dramatic apoptosis of neurons and radial glia. $\boldsymbol{A}-\boldsymbol{F}$, Coronal sections from Emx $1-C r e(A, C, E)$ and $E m \times 1-C r e ; R b m 8 a^{\text {loxp } /+}(\boldsymbol{B}, \mathbf{D}, \boldsymbol{F})$ dorsal neocortices from E11.5 $(\boldsymbol{A}, \boldsymbol{B})$ and E12.5 (C-F) embryos and stained for Tuj1 (green) and Hoechst (blue), CC3 (red), or TUNEL (red). $\boldsymbol{G}$, A higher magnification image of framed region in $\boldsymbol{F}$ showing costaining of TUNEL with

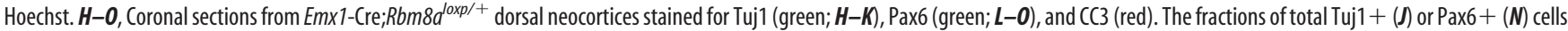
that are $(C 3+$ (apoptotic) are listed. Note a higher fraction of neurons are $C(3+$ compared with radial glia. $\boldsymbol{K}, \mathbf{0}$, High-magnification images of the regions boxed in $\boldsymbol{J}(\boldsymbol{K})$ and in $\boldsymbol{N}(\mathbf{0})$. Note images representing the $X-Z$ (left-right) and $Y-Z$ (top-bottom) planes are shown to demonstrate colocalization. All images were taken from dorsolateral regions at the medial rostrocaudal position represented in Figure 1D. $n=3$ biological replicates each, representative images were shown. Scale bars: $A-J, L-N, 50 \mu \mathrm{m} ; \boldsymbol{K}, \mathbf{0} ; 10 \mu \mathrm{m}$.

$8 E-H, K)$. In contrast, the density of Tbr1-positive layer VI neurons was not significantly reduced in Emxl-Cre;Rbm $8 a^{\text {loxp } /+}$ brains (Fig. 8I-K). However, although Tbr1 neuronal density was not affected, Tbr1-positive neurons were inappropriately distributed throughout the cortical tissue $(p<0.0001$; Fig. $8 I, J, L)$. The dramatic reduction in outer layer neurons is consistent with depleted progenitor populations seen at E12.5 and E13.5. Our analyses demonstrate an essential requirement for $R b m 8 a$ in neurogenesis and brain size, with microcephaly explained by aberrant progenitor proliferation and severe apoptosis.

\section{RBM8A overexpression does not dramatically perturb neurogenesis or increase head size}

The data presented herein show that Rbm8a is essential for proper neurogenesis and brain size. RBM8A is located in the proximal 1q21.1 CNV, in which both microdeletions and microduplications are associated with brain malformations including microcephaly and macrocephaly (Brunetti-Pierri et al., 2008; Mefford et al., 2008; Rosenfeld et al., 2012). Given this association and the report of micro/macrocephaly in some patients with TAR syndrome, we next asked whether Rbm8a overexpression could have a reciprocal impact upon neurogenesis to that observed with $R b m 8 a$ haploinsufficiency.

To first test this hypothesis, we performed in utero electroporation to express Flag-tagged human RBM8A in E13.5 dorsal cortices and subsequently analyzed neurogenesis at E16.5. Between E13.5 and E16.5, radial glial progenitors mainly produce neurons, which migrate to the cortical plate. Therefore we reasoned that if $R B M 8 A$ overexpression impacts neurogenesis, at these stages dramatic differences in progeny distribution and/or number should be evident. Aberrant distribution can be indicative of defective neuronal migration or progenitor proliferation. We coelectroporated EGFP to mark electroporated cells with either RBM8A or empty vector, as a control (Fig. $9 A-D$ ). Using coronal sections of E16.5 electroporated brains, we quantified the distribution of EGFP-positive cells, which marks both electroporated progenitors and their progeny. Comparison of control versus RBM8A electroporated brains revealed no significant difference in the distribution of EGFP-positive cells in the CP, IZ, or 

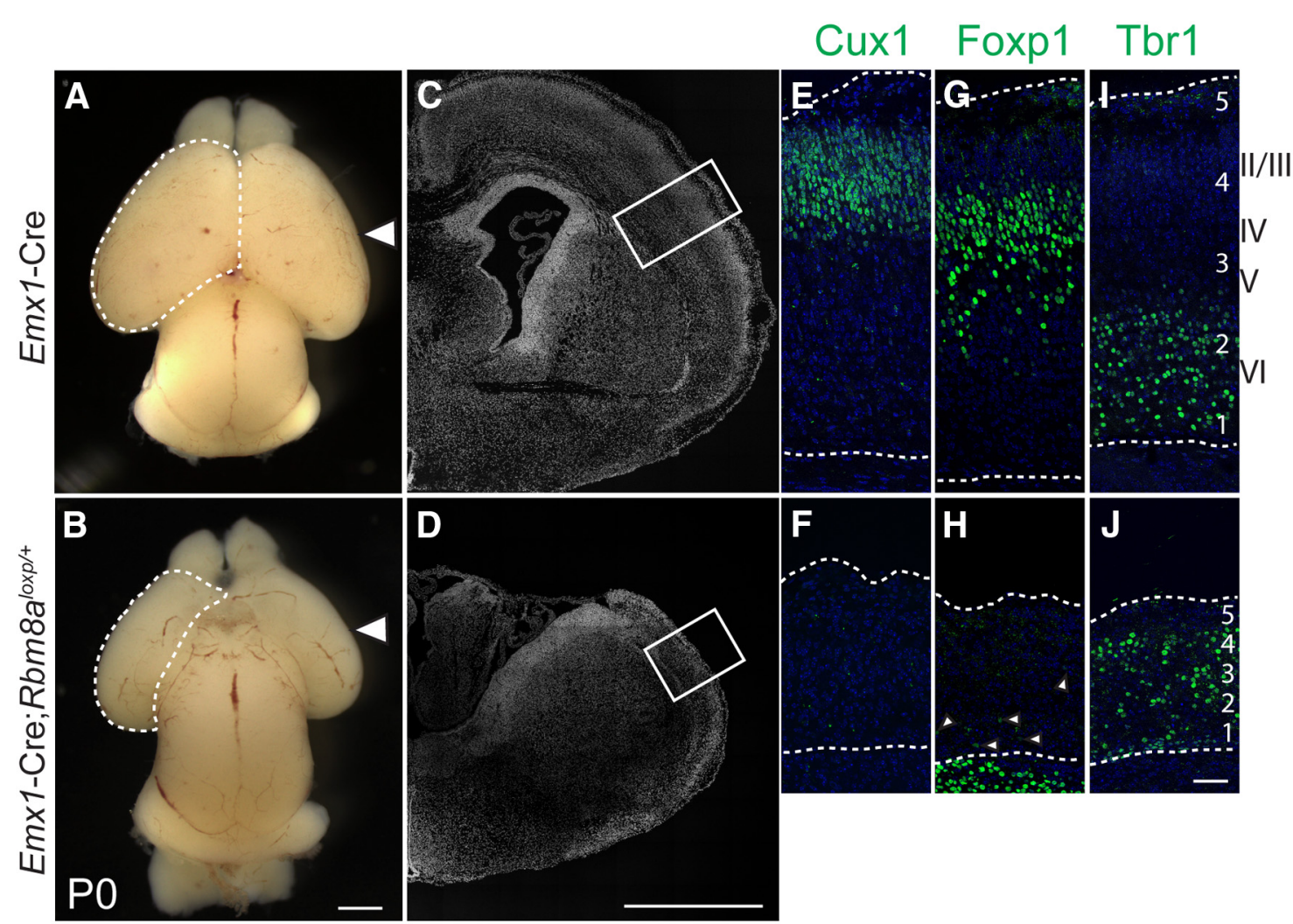

K
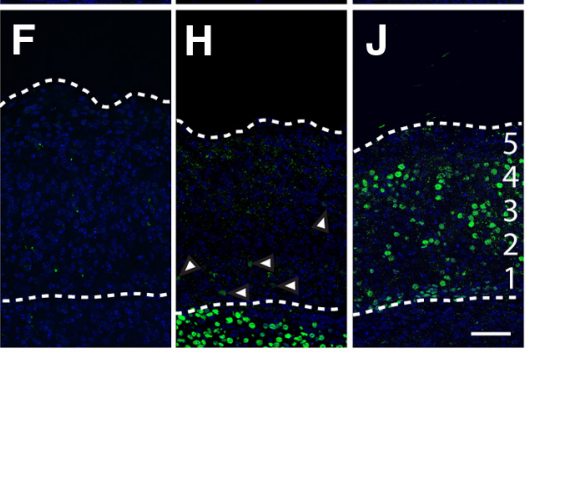

Emx1-Cre

Emx1-Cre;Rbm8a

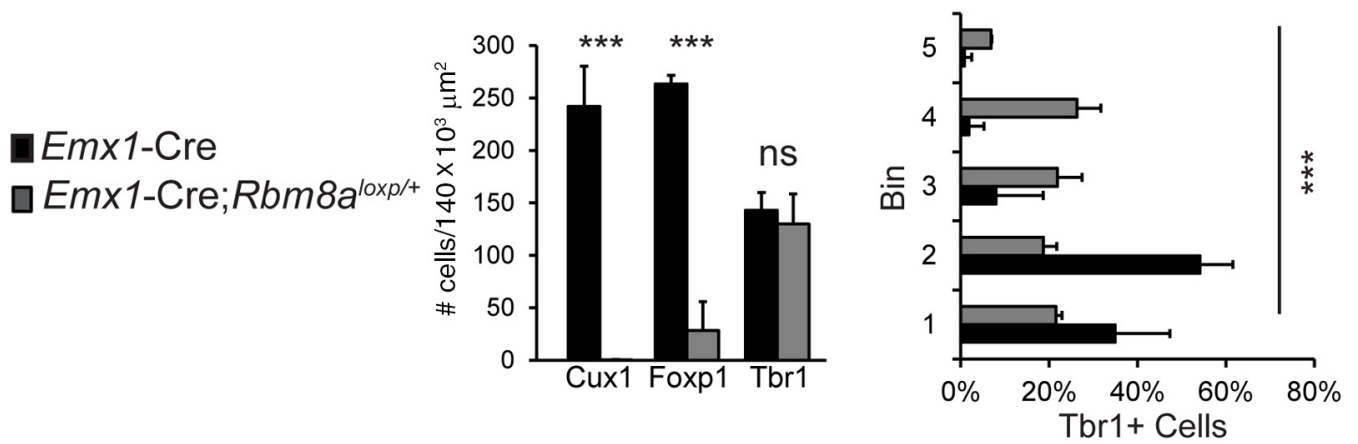

$\mathbf{L}$

Figure 8. Rbm8a haploinsufficiency disrupts cortical lamination. $\boldsymbol{A}, \boldsymbol{B}$, Whole-mount P0 brains from indicated genotypes. Dotted circles denote dorsal cortices. $\boldsymbol{C}, \boldsymbol{D}$, Coronal sections of Hoechst-stained P0 brains from indicated genotypes (plane indicated by arrowheads in $\boldsymbol{A}$ and $\boldsymbol{B})$. $\boldsymbol{E}-\boldsymbol{J}$, Coronal sections of P0 Emx 1 -Cre $(\boldsymbol{E}, \boldsymbol{G}, \boldsymbol{I})$ and $E m \times 1$-Cre; $R b m 8 a^{\text {loxp } /+}(\boldsymbol{F}, \boldsymbol{H}, \boldsymbol{J})$ stained for $\mathrm{Cux} 1$ $(\boldsymbol{E}, \boldsymbol{F})$, Foxp $1(\boldsymbol{G}, \boldsymbol{H})$, and $\operatorname{Tbr} 1(\boldsymbol{I}, \boldsymbol{J})$ at regions indicated in $\boldsymbol{C}$ and $\boldsymbol{D}$. Dotted lines demarcate dorsal cortex. Neuronal layers (layers $\|-V)$ are indicated. Arrowheads indicate Foxp1+ cells in the dorsal

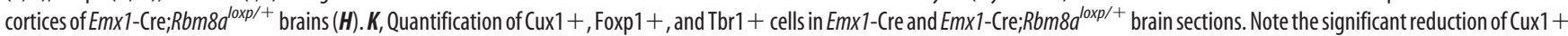
and Foxp1+ cells observed in Emx1-Cre;Rbm8d ${ }^{\text {loxp/+ }}$ brains. L, Fraction of Tbr1+ cells located in bins (as indicated in Fig. 8/,) with bin 5 most pial and bin 1 adjacent to the ventricle. Note the distribution of Tbr1 + is significantly different between $E m \times 1$-Cre and Emx 1 -Cre:Rbm8 $a^{\text {loxp } /+}$ brains. $\boldsymbol{K}$, Student's $t$ test. $\boldsymbol{L}, \chi^{2}$ analysis, ns, $p=0.517,{ }^{* * *} p<0.0001$. Error bars indicate SD, $n=$ 3 biological replicates each. Scale bars: $\boldsymbol{A}-\boldsymbol{D}, 1 \mathrm{~mm} ; \boldsymbol{E}-\boldsymbol{J}, 50 \mu \mathrm{m}$.

SVZ/VZ layers $(~ p=0.999 ;$ Fig. 9D). Expression of Flag-tagged $R B M 8 A$ was detectable in EGFP-positive cells as evidenced with either anti-Flag staining or anti-RBM8A staining (Fig. 9E-Q). This indicates RBM8A overexpression in E13.5 progenitors does not overtly impact distribution of progenitors and progeny.

Because Rbm8a haploinsufficiency caused depletion of both radial glia and IPs, we asked if RBM8A overexpression affects these populations. We quantified the proportion of EGFP-positive cells that colocalize with either Pax6 or Tbr2 (Fig. $9 R-W, B B$ ). Neither radial glial progenitor nor IP number were significantly impacted by $R B M 8 A$ overexpression $(p=$ 0.261 and 0.893 , respectively; Fig. $9 B B$ ). Although we quantified no difference in distribution of transfected cells, it is possible there could be defects in either proliferation and/or apoptosis associated with RBM8A overexpression. For example, decreased apoptosis is associated with macrocephaly (Haydar et al., 1999). However, analysis of CC3 staining revealed no evidence of decreased apoptosis upon RBM8A overexpression (data not shown). We also examined whether RBM8A could impact proliferation by quantifying the fraction of EGFP-positive cells that colocalize with $\mathrm{PH} 3$ (Fig. 9X-BB). We observed no significant difference between control and RBM8A overexpression brains $(p=0.525)$. Due to the timing of electroporation, we cannot exclude the possibility that RBM8A overexpression impacts earlier stages of neurogenesis. However, the lack of any defects in EGFP distribution, progenitor fractions, or proliferation suggests overexpression of RBM8A in E13.5 progenitors does not grossly impact the number of radial glia or IPs. 


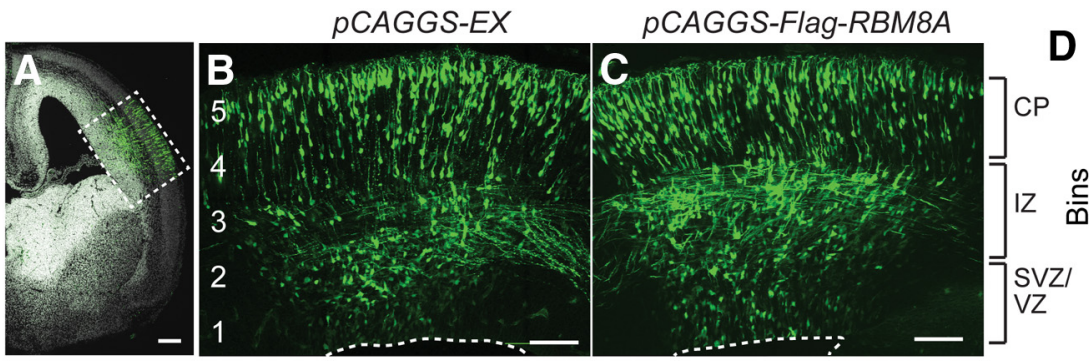

E13.6-->E16.5

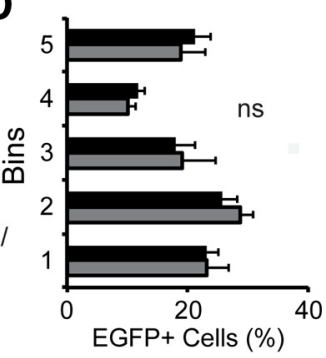

חpCAGGS-EX

I pCAGGS-Flag-RBM8A
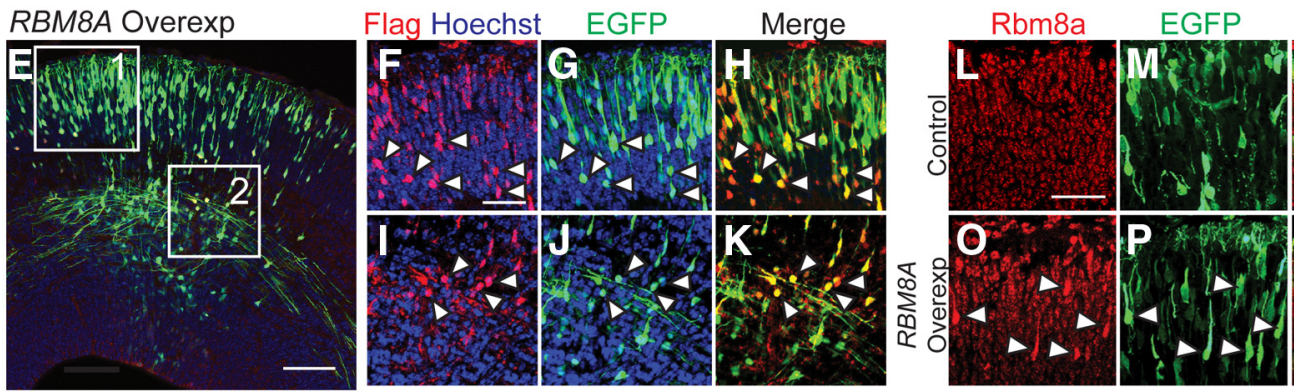

Merge
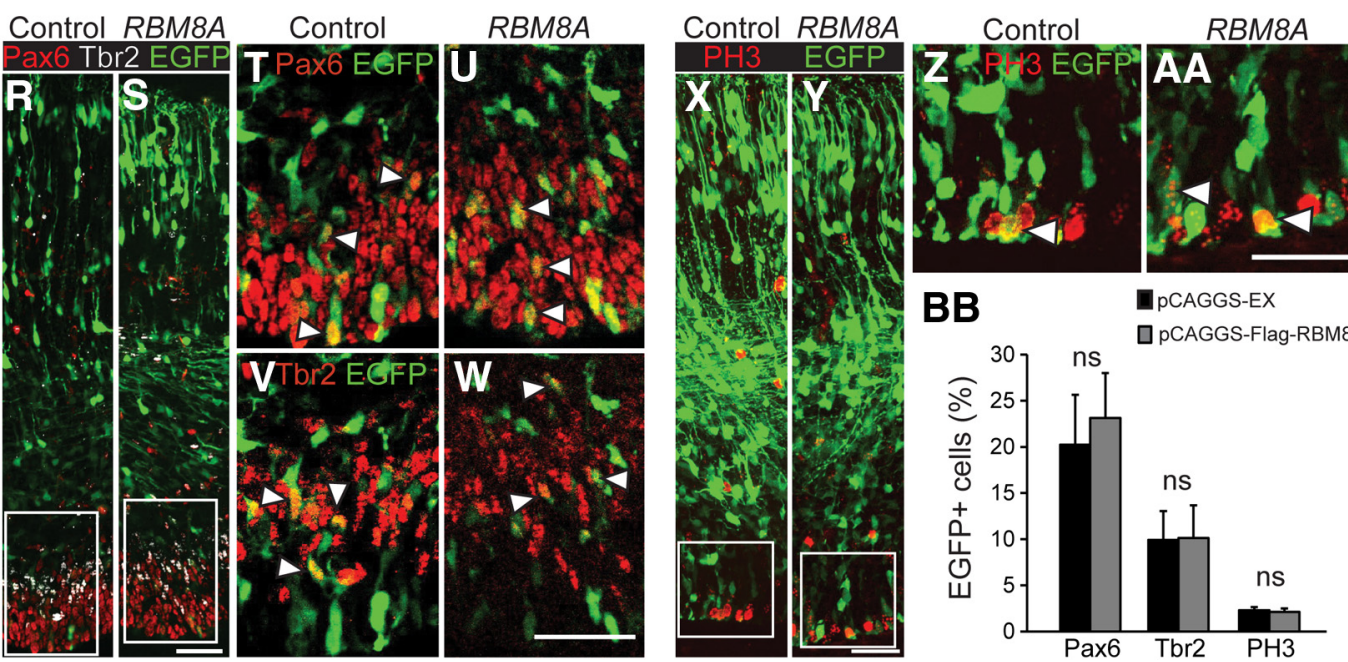

Figure 9. Overexpression of RBM8A does not impact distribution of cells in the developing neocortex. $A-C$, Coronal sections of E16.5 brains, in utero electroporated at E13.5 with representative electroporated region $(\boldsymbol{A})$, with pCAGGS-EGFP plus either PCAGGS-EX (B) or pCAGGS-Flag-RBM8A (C). Numbers indicate bins for quantitation in $\boldsymbol{D}$ and brackets indicate CP, IZ, and SVZ/VZ. D, Quantitation of distribution of EGFP-positive cells in five bins for cortices; with bin 5 most pial and bin 1 adjacent to the ventricle. Note there was no significant difference in the distribution of GFP-positive cells between control and RBM8A electroporated brains. $\boldsymbol{E}$, Coronal section of an E16.5 brain electroporated with pCAGGS-Flag-RBM8A (RBM8A overexp.). $\boldsymbol{F}$ - $\boldsymbol{K}$, Higher magnification images of region $1(\boldsymbol{F}-\boldsymbol{H})$ and region $2(\boldsymbol{I}-\boldsymbol{K})$ stained for anti-FLAG (red; $\boldsymbol{F}, \boldsymbol{I})$, EGFP (green), and Hoechst (blue; $\boldsymbol{G}, \boldsymbol{J})$ and merge $(\boldsymbol{H}, \boldsymbol{K})$. Arrowheads, electroporated EGFP cells coexpressing FLAG (yellow). Note high FLAG expression in electroporated cells. $\mathbf{L}-\mathbf{Q}$, Coronal sections of E16.5 electroporated with pCAGGS-EGFP and either $p C A G G S-E X$ ( $\mathbf{L}-\mathbf{M}$, control) or pCAGGS-Flag-RBM8A (0-Q, RBM8A overexp.) and stained for Rbm8a (red; $\boldsymbol{L}, \mathbf{O})$, EGFP (green; $\boldsymbol{M}, \boldsymbol{P})$, and merge ( $\boldsymbol{N}, \boldsymbol{Q})$. Arrowheads, electroporated EGFP cells showing high Rbm8a staining in $p C A G G S-F l a g-R B M 8 A$ cells (yellow), but not in $p$ CAGGS-EX transfected cells. $\boldsymbol{R}$, $\boldsymbol{S}$, Coronal sections of E16.5 brains electroporated with $p$ CAGGS-EGFP and either $p$ CAGGS-EX ( $\boldsymbol{R}$, control) or $p$ CAGGS-Flag-RBM8A (S, RBM8A) and stained for anti-Pax6 (red) and anti-Tbr2 (gray). $\boldsymbol{T}-\boldsymbol{W}$, High-magnification images of regions indicated in $\boldsymbol{R}(\boldsymbol{T}, \boldsymbol{V})$ and $\boldsymbol{S}(\boldsymbol{U}, \boldsymbol{W})$ and stained with either anti-Pax6 (red; $\boldsymbol{T}, \boldsymbol{U})$ or anti-Tbr2 (red; $\boldsymbol{V}, \boldsymbol{W})$. Arrowheads, EGFP+ cells (yellow) costained with either Pax6 $(\boldsymbol{T}, \boldsymbol{U})$ or Tbr2 $(\boldsymbol{V}, \boldsymbol{W}) . \boldsymbol{X}, \boldsymbol{Y}$, Coronal sections of E16.5 brains electroporated with pCAGGS-EGFP (green) and either pCAGGS-EX (X, control) or pCAGGS-Flag-RBM8A ( $\boldsymbol{Y}, R B M 8 A)$ and stained for anti-PH3 (red). $Z$, $A A$, High-magnification images of regions indicated in $\boldsymbol{X}(\boldsymbol{Z})$ and $\boldsymbol{Y}(\boldsymbol{A} \boldsymbol{A})$, and stained for anti-PH3 (red). Arrowheads, EGFP + cells costained with PH3 (yellow). BB, Fractions of EGFP + cells costained with Pax6, Tbr2, or PH3. Note there was no significant difference between control and RBM8A electroporated brains. $\boldsymbol{D}$, $\chi^{2}$ analysis. $B B$, Student'st test, ns, $p>0.2$. Error bars indicate $S D, n=3$ biological replicates each condition. For each biological replicate, three to four sections were quantified. $S c a l e$ bars: $A, 200 \mu \mathrm{m}$; $B, C, E, 100 \mu \mathrm{m} ; F-A A, 50 \mu \mathrm{m}$.

To independently assess whether RBM8A overexpression leads to head size and neuronal defects, we used zebrafish to overexpress the human RBM8A mRNA at the one- to two-cell stage. We have shown previously that head size with concomitant neurogenesis defects in zebrafish embryos represents a useful surrogate for the evaluation of loci associated with neurocognitive traits in humans (Golzio et al., 2012; Beunders et al., 2013; Suga- than et al., 2014). For example, overexpression and knockdown of KCTD13, a locus within the 16p11.2 CNV, induces microcephaly and macrocephaly in zebrafish, respectively, and these data have been since corroborated independently by association studies in large cohorts (Golzio et al., 2012; Fromer et al., 2014). We overexpressed human RBM8A mRNA in fertilized eggs and evaluated gross morphometric and cell-specific characteristics of 

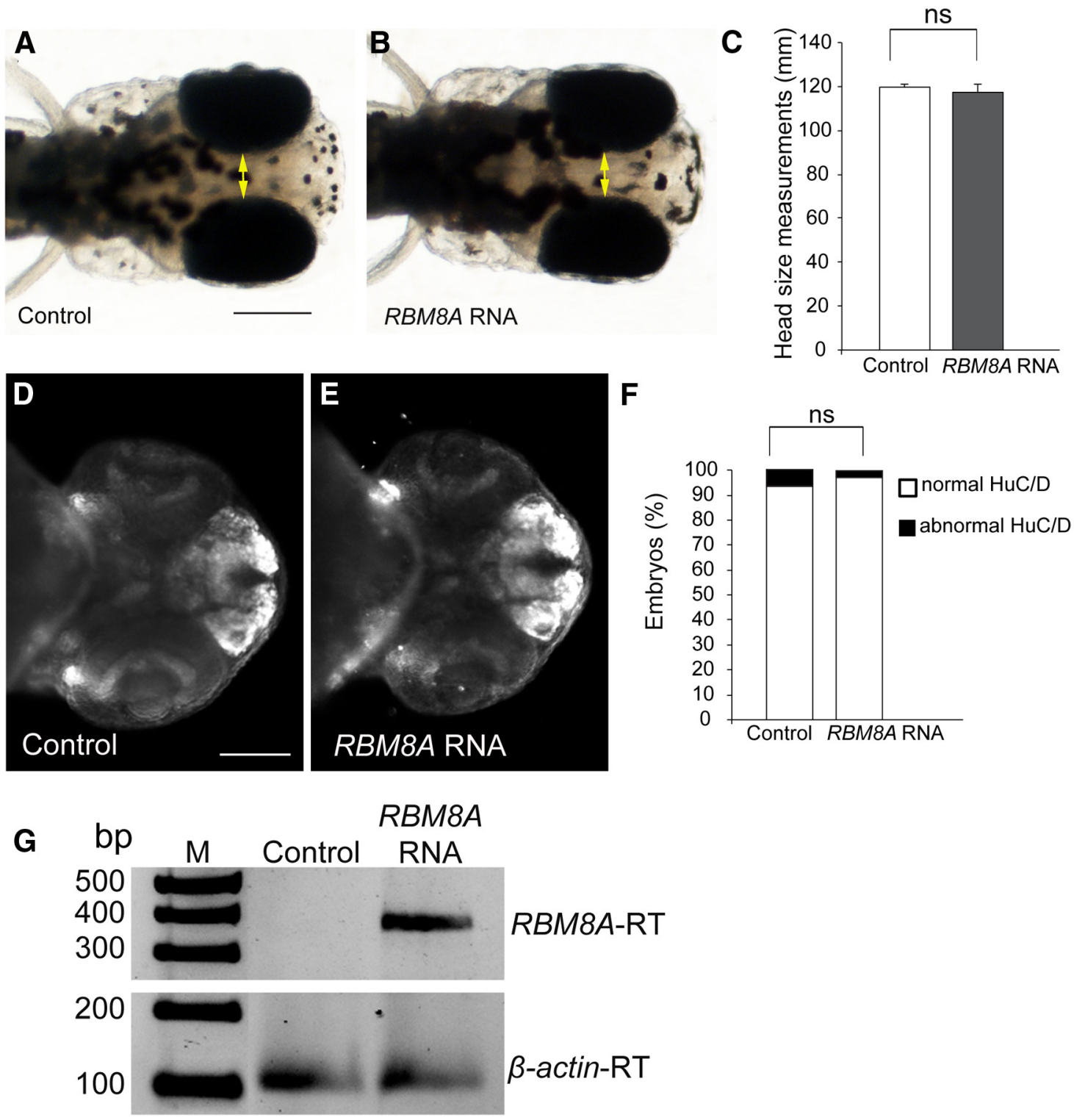

Figure 10. RBM8A-injected embryos have normal head size and HuC/D expression in the forebrain. $\boldsymbol{A}, \boldsymbol{B}$, Representative images show dorsal views of a sham-injected control $(\boldsymbol{A})$ and an embryo injected with human RBM8A RNA (B).C, Quantification of head size by measuring the distance across the convex tip of the eyecups (yellow arrows) at 4.5 dpf. Note $R B M 8 A$ RNA-injected embryos have normal head size, $p=0.46$, Student's $t$ test. $\boldsymbol{D}, \boldsymbol{E}$, Representative images showing HuC/D-antibody staining and ventral views of a sham-injected control (D) and RBM8A-injected embryo at 2 dpf (E). Note HuC/D expression is bilateral and restricted to the roof plate of the neural tube in the forebrain at $2 \mathrm{dpf}$ in both $R B M 8 A$ overexpressants and controls. $F$, Percentage of embryos with normal (bilateral) or abnormal (unilateral) HuC/D staining in the anterior forebrain. Note embryos injected with RBM8A exhibit normal bilateral expression of HuC/D compared with controls $(p=0.75$, Fisher exact test,). G, RT-PCR using human RBM8A and zebrafish $\beta$-actin primers on RNA extracted from control and RBM8A mRNA-injected embryos at 2 dpf. M, marker ( $1 \mathrm{~kb}$ plus ladder). Error bars indicate SEM, $n=60$ embryos per group; experiments repeated three times. Scale bars: $200 \mu \mathrm{m}$.

overexpressants at 2 and $4.5 \mathrm{dpf}$. Masked quantitative scoring of RBM8A RNA-injected embryos at $4.5 \mathrm{dpf}$ showed no significant difference of head size between RBM8A RNA-injected embryos and controls ( $p=0.46$; Fig. $10 A-C$ ). Because RBM8A overexpression could perturb neurogenesis without affecting head size, we stained embryos at $2 \mathrm{dpf}$ with anti-HuC/D, to mark postmitotic neurons (Grandel et al., 2006; Golzio et al., 2012; Beunders et al., 2013). We observed a normal bilateral distribution of $\mathrm{HuC} / \mathrm{D}$ in the forebrain in RBM8A overexpressants that was indistinguishable from that of control embryos from the same clutch $(p=0.75$; Fig. $10 D-F)$. This is consistent with lack of any defect in early stages of neuronal differentiation or migration. Finally, to exclude the possibility that the absence of phenotype was due to degradation of the RBM $8 A$ RNA, we extracted total
RNA from injected embryos and performed RT-PCR with human $R B M 8 A$ primers. We could detect the $R B M 8 A$-injected RNA at $2 \mathrm{dpf}$ and up to $4.5 \mathrm{dpf}$ (Fig. $10 \mathrm{G}$; data not shown). These data indicate that overexpression of $R B M 8 A$ does not perturb neuronal differentiation at early developmental stages and is unlikely responsible for head size defects in patients with a duplication of RBM8A.

\section{Discussion}

In this study we demonstrate that the exon junction complex component $R b m 8 a$ is essential for embryonic neurogenesis and proper brain size in mice. $R b m 8 a$ haploinsufficiency causes microcephaly, due to progenitor depletion and massive neuronal apoptosis. Hence $R b m 8 a$ is a critical regulator for neural progenitor maintenance, dif- 
ferentiation, and brain size. Our study highlights $R B M 8 A$ as a critical gene that may contribute to neurodevelopmental phenotypes associated with proximal 1q21.1 microdeletions.

\section{Mechanisms of $R b m 8 a$ function in neurogenesis and microcephaly}

We show that $R b m 8 a$ haploinsufficiency causes microcephaly due to depletion of both progenitors and neurons, ultimately leading to severe cortical lamination defects including loss of virtually all upper layer neurons. Our study elucidates two mechanisms to explain how these populations are perturbed. First we discovered that $R b m 8 a$ regulates radial glia proliferation, preventing premature cell-cycle exit and neuronal differentiation. As a result $R b m 8 a$ depletion causes accelerated neurogenesis by radial glia, resulting in a striking reduction in progenitor pools along with significantly more neurons. A second mechanism by which $R b m 8 a$ regulates brain size is via apoptosis, which in the mutant occurs largely in ectopic neurons, but is also evident to a lesser extent within radial glia. Apoptosis is a common microcephaly phenotype and is associated frequently with ectopic neuron production (Yingling et al., 2008; Kim et al., 2010; Silver et al., 2010; Marthiens et al., 2013; Insolera et al., 2014). Our data indicate that a combination of altered progenitor division and apoptosis of progeny contribute to the severe loss of dorsal cortex and ultimately microcephaly.

How do defects in radial glia proliferation initially impact progenitor and neuron number? We speculate that $R b m 8 a$ influences the balance of proliferative and neurogenic divisions of radial glia, leading to production of neurons at the expense of progenitors. As shown previously by our group, $R b m 8 a$ is required for proper cell division (Silver et al., 2010). More $G_{2} / M$ progenitors could indicate a faster overall cell cycle with a similar $\mathrm{G}_{2} / \mathrm{M}$ length or a prolonged $\mathrm{G}_{2} / \mathrm{M}$ with identical cell-cycle duration. As cell cycle has been linked to cell fate in the developing brain (Lange et al., 2009; Pilaz et al., 2009; Arai et al., 2011), it is plausible that cell-cycle defects could influence production of neurons and progenitors. Interestingly, while $\mathrm{PH} 3+$ progenitors were increased, the proportion of cycling Ki67+ progenitors decreased. This reduction in total cycling progenitors may be attributed to any of the following possibilities, which are not mutually exclusive: massive progenitor apoptosis, increased cell-cycle exit, and depletion of progenitor production. Future studies will help determine the detailed cellular and molecular mechanisms by which $R b m 8 a$ influences progenitor number as well as apoptosis. Of note, RBM8A joins a growing repertoire of RNA binding proteins implicated in these aspects of corticogenesis, as discussed in a recent review (DeBoer et al., 2013).

RBM8A forms a tight heterodimer with MAGOH as part of the EJC (Lau et al., 2003; Tange et al., 2005; Bono et al., 2006; Gehring et al., 2009); therefore, it is reasonable to predict that haploinsufficiency phenotypes would be similar. In support of this hypothesis, both Rbm8a and Magoh have similar expression patterns in the developing cortex. In addition, the temporal onset of Rbm8a and Magoh haploinsufficiency phenotypes, including apoptosis, reduced intermediate progenitors, and ectopic neurons are also similar (Silver et al., 2010). However, in contrast to Magoh haploinsufficiency models (Silver et al., 2010; McMahon et al., 2014), Rbm8a haploinsufficient mice display a more severe microcephaly. A careful comparison of neurogenesis phenotypes indicates that the major difference is $R b m 8 a$ mutants have more extensive apoptosis of both neurons and radial glia. But why might Rbm8a and Magoh haploinsufficiency induce varying severity of apoptosis? One possibility is protein levels; Emx1-Cre;
Magoh $^{\text {loxp/+ }}$ and germline $\mathrm{Magoh}^{+/-}$brains have 50\% reduced MAGOH protein levels (Silver et al., 2010; McMahon et al., 2014), whereas Emx1-Cre; Rbm8a $a^{\text {loxp } /+}$ cortices showed a $70 \%$ RBM8A reduction. Clearly the dosage of these genes is important, thus a higher fold reduction of either Magoh or Rbm8a could be more detrimental for neurogenesis. Another explanation for the difference is redundancy; mice have only one $\mathrm{Rbm} 8 \mathrm{a}$ homolog, yet they have two Magoh homologs, which are virtually identical in sequence (Silver et al., 2010, 2013; Singh et al., 2013). Although Magohb is expressed at lower levels than Magoh in the embryonic brain, it could compensate for reduced Magoh levels. A third possibility is that either $R b m 8 a$ and/or Magoh have functions independent of the EJC or each other. Indeed there are some indications of noncanonical functions for both genes, in regulating signaling (Muromoto et al., 2009; Togi et al., 2013). Future genetic studies perturbing additional EJC components will be valuable to determine whether RBM8A impacts neurogenesis via the EJC or not and if so which aspects of EJC function are dysregulated during cortical development.

\section{Rbm8a dosage in neurodevelopmental disease}

We demonstrate that $R b m 8 a$ haploinsufficiency perturbs brain size, which is consistent with human genetic studies showing a strong association between reduced RBM8A copy number and neurodevelopmental disorders. Copy number losses of $R B M 8 A$ are significantly enriched in patients with neurodevelopmental disorders, including microcephaly (Albers et al., 2012; Nguyen et al., 2013). Moreover, microdeletions of the proximal 1q21.1 region, where $R B M 8 A$ resides, are associated with microcephaly, intellectual disability, behavioral abnormalities, and seizures (Sharp et al., 2006; Brunetti-Pierri et al., 2008; International Schizophrenia Consortium, 2008; Mefford et al., 2008; Rosenfeld et al., 2012; Nguyen et al., 2013). Patients with TAR syndrome, a blood and skeletal disorder attributed to compound mutations of $R B M 8 A$, present with and without these brain malformations (Nguyen et al., 2013, 2014). We speculate that different genetic backgrounds and potential effects (trans- and cis-) from genes expressed within the larger 1q21.1 region (BP3-BP4) could contribute to the co-occurrence of blood/skeletal defects and neurodevelopmental phenotypes in TAR patients. For example, there is precedence for genetic interactions between genes located within CNVs and for trans-effects of deletion/duplications upon neighboring gene expression (Blumenthal et al., 2014; Carvalho et al., 2014). Regardless, our study highlights $R B M 8 A$ as a strong causal candidate gene for brain-related phenotypes associated with the proximal 1q21.1 microdeletions. We obtained $70 \%$ reduction of $R b m 8 a$ expression in the mouse haploinsufficiency model, simulating a heterozygous deletion of RBM $8 A$ in humans. This new mouse model will be a valuable in vivo tool to determine how RBM8A loss impacts the etiology of neurodevelopmental phenotypes, including the cellular and behavioral basis.

Remarkably, dosage gains of RBM $8 A$ are also associated with neurodevelopmental phenotypes. CNV gains in $R B M 8 A$, as well as microduplications of the proximal 1q21.1 region (BP2-BP3), are associated with intellectual disability, autism, and brain malformations such as macrocephaly (Sharp et al., 2006; BrunettiPierri et al., 2008; International Schizophrenia Consortium, 2008; Mefford et al., 2008; Rosenfeld et al., 2012; Nguyen et al., 2013). We found that although loss of one Rbm8a allele led to severe neurogenesis defects, neurogenesis or head size were obviously affected by $R b m 8 a$ overexpression. Our data from two model organisms suggest that $R b m 8 a$ overexpression might not be a major contributor to macrocephaly in human patients with 
microduplications of the proximal region of 1q21.1. Instead, given that $R b m 8 a$ is also expressed in postmitotic neurons, we speculate that copy number gains might impact mature neuronal functions such as synapse development (Alachkar et al., 2013).

EJC components have collectively emerged as critical for neurodevelopmental disorders. In addition to RBM8A, altered gene dosage of additional EJC components, including EIF4A3, UPF3A, and $U P F 3 B$, are seen in patients presenting with intellectual disability and brain malformations (Tarpey et al., 2007; Addington et al., 2011; Nguyen et al., 2013). Noncoding EIF4A3 mutations cause Richieri-Costa-Pereira syndrome, a craniofacial disorder associated with neurological deficits (Favaro et al., 2014). In addition, coding mutations in $U P F 3 B$ cause intellectual disability, schizophrenia, and autism (Tarpey et al., 2007; Addington et al., 2011). However, mechanisms underlying neurodevelopmental pathologies for these disorders still remain elusive. By uncovering a critical requirement for the EJC component RBM8A in cortical development, our study helps provide important insights into how this essential molecular complex contributes to the etiology of neurodevelopmental disorders.

\section{References}

Addington AM, Gauthier J, Piton A, Hamdan FF, Raymond A, Gogtay N, Miller R, Tossell J, Bakalar J, Inoff-Germain G, Gochman P, Long R, Rapoport JL, Rouleau GA (2011) A novel frameshift mutation in UPF3B identified in brothers affected with childhood onset schizophrenia and autism spectrum disorders. Mol Psychiatry 16:238-239. CrossRef Medline

Alachkar, A, Jiang, D, Harrison, M, Zhou, Y, Chen, G, and Mao, Y (2013) An EJC factor RBM8a regulates anxiety behaviors. Curr Mol Med 6:887-899. Medline

Albers CA, Paul DS, Schulze H, Freson K, Stephens JC, Smethurst PA, Jolley JD, Cvejic A, Kostadima M, Bertone P, Breuning MH, Debili N, Deloukas P, Favier R, Fiedler J, Hobbs CM, Huang N, Hurles ME, Kiddle G, Krapels I, et al. (2012) Compound inheritance of a low-frequency regulatory SNP and a rare null mutation in exon-junction complex subunit RBM8A causes TAR syndrome. Nat Genet 44:435-439, S1-S2. CrossRef Medline

Arai Y, Pulvers JN, Haffner C, Schilling B, Nüsslein I, Calegari F, Huttner WB (2011) Neural stem and progenitor cells shorten S-phase on commitment to neuron production. Nat Commun 2:154. CrossRef Medline

Ashton-Beaucage D, Udell CM, Lavoie H, Baril C, Lefrançois M, Chagnon P, Gendron P, Caron-Lizotte O, Bonneil E, Thibault P, Therrien M (2010) The exon junction complex controls the splicing of MAPK and other long intron-containing transcripts in Drosophila. Cell 143:251-262. CrossRef Medline

Ayoub AE, Oh S, Xie Y, Leng J, Cotney J, Dominguez MH, Noonan JP, Rakic P (2011) Transcriptional programs in transient embryonic zones of the cerebral cortex defined by high-resolution mRNA sequencing. Proc Natl Acad Sci U S A 108:14950-14955. CrossRef Medline

Beunders G, Voorhoeve E, Golzio C, Pardo LM, Rosenfeld JA, Talkowski ME, Simonic I, Lionel AC, Vergult S, Pyatt RE, van de Kamp J, Nieuwint A, Weiss MM, Rizzu P, Verwer LE, van Spaendonk RM, Shen Y, Wu BL, Yu T, Yu Y, et al. (2013) Exonic deletions in AUTS2 cause a syndromic form of intellectual disability and suggest a critical role for the C terminus. Am J Hum Genet 92:210-220. CrossRef Medline

Blumenthal I, Ragavendran A, Erdin S, Klei L, Sugathan A, Guide JR, Manavalan P, Zhou JQ, Wheeler VC, Levin JZ, Ernst C, Roeder K, Devlin B, Gusella JF, Talkowski ME (2014) AR TICLETranscriptional consequences of 16p11.2 deletion and duplication in mouse cortex and multiplex autism families. Am J Hum Genet 94:870-883. CrossRef Medline

Bono F, Gehring NH (2011) Assembly, disassembly and recycling: the dynamics of exon junction complexes. RNA Biol 8:24-29. CrossRef Medline

Bono F, Ebert J, Lorentzen E, Conti E (2006) The crystal structure of the exon junction complex reveals how it maintains a stable grip on mRNA. Cell 126:713-725. CrossRef Medline

Brunetti-Pierri N, Berg JS, Scaglia F, Belmont J, Bacino CA, Sahoo T, Lalani SR, Graham B, Lee B, Shinawi M, Shen J, Kang SH, Pursley A, Lotze T, Kennedy G, Lansky-Shafer S, Weaver C, Roeder ER, Grebe, TA, Arnold GL, et al. (2008) Recurrent reciprocal 1q21.1 deletions and duplications associated with microcephaly or macrocephaly and developmental and behavioral abnormalities. Nat Genet 40:1466-1471. CrossRef Medline

Carvalho CM, Vasanth S, Shinawi M, Russell C, Ramocki MB, Brown CW, Graakjaer J, Skytte AB, Vianna-Morgante AM, Krepischi AC, Patel GS, Immken L, Aleck K, Lim C, Cheung SW, Rosenberg C, Katsanis N, Lupski JR (2014) Dosage changes of a segment at 17p13.1 lead to intellectual disability and microcephaly as a result of complex genetic interaction of multiple genes. Am J Hum Genet 95:565-578. CrossRef Medline

Chen JF, Zhang Y, Wilde J, Hansen KC, Lai F, Niswander L (2014) Microcephaly disease gene Wdr62 regulates mitotic progression of embryonic neural stem cells and brain size. Nat Commun 5:3885. CrossRef Medline

Chou SJ, Perez-Garcia CG, Kroll TT, O'Leary DD (2009) Lhx2 specifies regional fate in Emx1 lineage of telencephalic progenitors generating cerebral cortex. Nat Neurosci 12:1381-1389. CrossRef Medline

Daguenet E, Baguet A, Degot S, Schmidt U, Alpy F, Wendling C, Spiegelhalter C, Kessler P, Rio MC, Le Hir H, Bertrand E, Tomasetto C (2012) Perispeckles are major assembly sites for the exon junction core complex. Mol Biol Cell 23:1765-1782. CrossRef Medline

DeBoer EM, Kraushar ML, Hart RP, Rasin MR (2013) Post-transcriptional regulatory elements and spatiotemporal specification of neocortical stem cells and projection neurons. Neuroscience 248: 499-528. CrossRef Medline

Englund C, Fink A, Lau C, Pham D, Daza RA, Bulfone A, Kowalczyk T, Hevner RF (2005) Pax6, Tbr2, and Tbr1 are expressed sequentially by radial glia, intermediate progenitor cells, and postmitotic neurons in developing neocortex. J Neurosci 25:247-251. CrossRef Medline

Favaro FP, Alvizi L, Zechi-Ceide RM, Bertola D, Felix TM, de Souza J, Raskin S, Twigg SR, Weiner AM, Armas P, Margarit E, Calcaterra NB, Andersen GR, McGowan SJ, Wilkie AO, Richieri-Costa A, de Almeida ML, PassosBueno MR (2014) A noncoding expansion in EIF4A3 causes RichieriCosta-Pereira syndrome, a craniofacial disorder associated with limb defects. Am J Hum Genet 94:120-128. CrossRef Medline

Feng Y, Walsh CA (2004) Mitotic spindle regulation by Ndel controls cerebral cortical size. Neuron 44:279-293. CrossRef Medline

Fietz SA, Huttner WB (2011) Cortical progenitor expansion, self-renewal and neurogenesis-a polarized perspective. Curr Opin Neurobiol 21:23-35. CrossRef Medline

Franco SJ, Müller U (2013) Shaping our minds: stem and progenitor cell diversity in the mammalian neocortex. Neuron 77:19-34. CrossRef Medline

Fromer M, Pocklington AJ, Kavanagh DH, Williams HJ, Dwyer S, Gormley P, Georgieva L, Rees E, Palta P, Ruderfer DM, Carrera N, Humphreys I, Johnson JS, Roussos P, Barker DD, Banks E, Milanova V, Grant SG, Hannon E, Rose SA, et al. (2014) De novo mutations in schizophrenia implicate synaptic networks. Nature 506:179-184. CrossRef Medline

Gehring NH, Lamprinaki S, Hentze MW, Kulozik AE (2009) The hierarchy of exon-junction complex assembly by the spliceosome explains key features of mammalian nonsense-mediated mRNA decay. PLoS Biol 7:e1000120. CrossRef Medline

Golzio C, Willer J, Talkowski ME, Oh EC, Taniguchi Y, Jacquemont S, Reymond A, Sun M, Sawa A, Gusella JF, Kamiya A, Beckmann JS, Katsanis N (2012) KCTD13 is a major driver of mirrored neuroanatomical phenotypes of the 16p11.2 copy number variant. Nature 485:363-367. CrossRef Medline

Gorski JA, Talley T, Qiu M, Puelles L, Rubenstein JL, Jones KR (2002) Cortical excitatory neurons and glia, but not GABAergic neurons, are produced in the Emx1-expressing lineage. J Neurosci 22:6309-6314. Medline

Grandel H, Kaslin J, Ganz J, Wenzel I, Brand M (2006) Neural stem cells and neurogenesis in the adult zebrafish brain: origin, proliferation dynamics, migration and cell fate. Dev Biol 295:263-277. CrossRef Medline

Greig LC, Woodworth MB, Galazo MJ, Padmanabhan H, Macklis JD (2013) Molecular logic of neocortical projection neuron specification, development and diversity. Nat Rev Neurosci 14:755-769. CrossRef Medline

Haydar TF, Kuan CY, Flavell RA, Rakic P (1999) The role of cell death in regulating the size and shape of the mammalian forebrain. Cereb Cortex 9:621-626. CrossRef Medline

Hu WF, Chahrour MH, Walsh CA (2014) The diverse genetic landscape of neurodevelopmental disorders. Annu Rev Genomics Hum Genet 15:195213. CrossRef Medline

Insolera R, Bazzi H, Shao W, Anderson KV, Shi SH (2014) Cortical neuro- 
genesis in the absence of centrioles. Nat Neurosci 17:1528-1535. CrossRef Medline

International Schizophrenia Consortium (2008) Rare chromosomal deletions and duplications increase risk of schizophrenia. Nature 455:237241. CrossRef Medline

Kataoka N, Diem MD, Kim VN, Yong J, Dreyfuss G (2001) Magoh, a human homolog of Drosophila mago nashi protein, is a component of the splicing-dependent exon-exon junction complex. EMBO J 20:64246433. CrossRef Medline

Kim S, Lehtinen MK, Sessa A, Zappaterra MW, Cho SH, Gonzalez D, Boggan B, Austin CA, Wijnholds J, Gambello MJ, Malicki J, La Mantia AS, Broccoli V, Walsh CA (2010) The apical complex couples cell fate and cell survival to cerebral cortical development. Neuron 66:69-84. CrossRef Medline

Kowalczyk T, Pontious A, Englund C, Daza RA, Bedogni F, Hodge R, Attardo A, Bell C, Huttner WB, Hevner RF (2009) Intermediate neuronal progenitors (basal progenitors) produce pyramidal-projection neurons for all layers of cerebral cortex. Cereb Cortex 19:2439-2450. CrossRef Medline

Lancaster MA, Renner M, Martin CA, Wenzel D, Bicknell LS, Hurles ME, Homfray T, Penninger JM, Jackson AP, Knoblich JA (2013) Cerebral organoids model human brain development and microcephaly. Nature 501:373-379. CrossRef Medline

Lange C, Huttner WB, Calegari F (2009) Cdk4/cyclinD1 overexpression in neural stem cells shortens G1, delays neurogenesis, and promotes the generation and expansion of basal progenitors. Cell Stem Cell 5:320-331. CrossRef Medline

Lau CK, Diem MD, Dreyfuss G, Van Duyne GD (2003) Structure of the Y14-Magoh core of the exon junction complex. Curr Biol 13:933-941. CrossRef Medline

Marthiens V, Rujano MA, Pennetier C, Tessier S, Paul-Gilloteaux P, Basto R (2013) Centrosome amplification causes microcephaly. Nat Cell Biol 15: 731-740. CrossRef Medline

McMahon JJ, Shi L, Silver DL (2014) Generation of a Magoh conditional allele in mice. Genesis 52:752-758. CrossRef Medline

Mefford HC, Sharp AJ, Baker C, Itsara A, Jiang Z, Buysse K, Huang S, Maloney VK, Crolla JA, Baralle D, Collins A, Mercer C, Norga K, de Ravel T, Devriendt K, Bongers EM, de Leeuw N, Reardon W, Gimelli S, Bena F, et al. (2008) Recurrent rearrangements of chromosome 1q21.1 and variable pediatric phenotypes. N Engl J Med 359:1685-1699. CrossRef Medline

Muromoto R, Taira N, Ikeda O, Shiga K, Kamitani S, Togi S, Kawakami S, Sekine Y, Nanbo A, Oritani K, Matsuda T (2009) The exon-junction complex proteins, Y14 and MAGOH regulate STAT3 activation. Biochem Biophys Res Commun 382:63-68. CrossRef Medline

Nguyen LS, Kim HG, Rosenfeld JA, Shen Y, Gusella JF, Lacassie Y, Layman LC, Shaffer LG, Gécz J (2013) Contribution of copy number variants involving nonsense-mediated mRNA decay pathway genes to neurodevelopmental disorders. Hum Mol Genet 22:1816-1825. CrossRef Medline

Nguyen LS, Wilkinson MF, Gecz J (2014) Nonsense-mediated mRNA decay: inter-individual variability and human disease. Neurosci Biobehav Rev 46:175-186. CrossRef Medline

Noctor SC, Flint AC, Weissman TA, Dammerman RS, Kriegstein AR (2001) Neurons derived from radial glial cells establish radial units in neocortex. Nature 409:714-720. CrossRef Medline

Palacios IM, Gatfield D, St Johnston D, Izaurralde E (2004) An eIF4AIIIcontaining complex required for mRNA localization and nonsensemediated mRNA decay. Nature 427:753-757. CrossRef Medline

Pilaz LJ, Patti D, Marcy G, Ollier E, Pfister S, Douglas RJ, Betizeau M, Gautier E, Cortay V, Doerflinger N, Kennedy H, Dehay C (2009) Forced G1phase reduction alters mode of division, neuron number, and laminar phenotype in the cerebral cortex. Proc Natl Acad Sci U S A 106:2192421929. CrossRef Medline

Roignant JY, Treisman JE (2010) Exon junction complex subunits are required to splice Drosophila MAP kinase, a large heterochromatic gene. Cell 143:238-250. CrossRef Medline
Rosenfeld JA, Traylor RN, Schaefer GB, McPherson EW, Ballif BC, Klopocki E, Mundlos S, Shaffer LG, Aylsworth AS, 1q21.1 Study Group (2012) Proximal microdeletions and microduplications of 1q21.1 contribute to variable abnormal phenotypes. Eur J Hum Genet 20:754-761. CrossRef Medline

Sahara S, O'Leary DD (2009) Fgf10 regulates transition period of cortical stem cell differentiation to radial glia controlling generation of neurons and basal progenitors. Neuron 63:48-62. CrossRef Medline

Saito T (2006) In vivo electroporation in the embryonic mouse central nervous system. Nat Protoc 1:1552-1558. CrossRef Medline

Sharp AJ, Hansen S, Selzer RR, Cheng Z, Regan R, Hurst JA, Stewart H, Price SM, Blair E, Hennekam RC, Fitzpatrick CA, Segraves R, Richmond TA, Guiver C, Albertson DG, Pinkel D, Eis PS, Schwartz S, Knight SJ, Eichler EE (2006) Discovery of previously unidentified genomic disorders from the duplication architecture of the human genome. Nat Genet 38:10381042. CrossRef Medline

Shibuya T, Tange TØ, Sonenberg N, Moore MJ (2004) eIF4AIII binds spliced mRNA in the exon junction complex and is essential for nonsensemediated decay. Nat Struct Mol Biol 11:346-351. CrossRef Medline

Silver DL, Watkins-Chow DE, Schreck KC, Pierfelice TJ, Larson DM, Burnetti AJ, Liaw HJ, Myung K, Walsh CA, Gaiano N, Pavan WJ (2010) The exon junction complex component Magoh controls brain size by regulating neural stem cell division. Nat Neurosci 13:551-558. CrossRef Medline

Silver DL, Leeds KE, Hwang HW, Miller EE, Pavan WJ (2013) The EJC component Magoh regulates proliferation and expansion of neural crestderived melanocytes. Dev Biol 375:172-181. CrossRef Medline

Singh KK, Wachsmuth L, Kulozik AE, Gehring NH (2013) Two mammalian MAGOH genes contribute to exon junction complex composition and nonsense-mediated decay. RNA Biol 10:1291-1298. CrossRef Medline

Sugathan A, Biagioli M, Golzio C, Erdin S, Blumenthal I, Manavalan P, Ragavendran A, Brand H, Lucente D, Miles J, Sheridan SD, Stortchevoi A, Kellis M, Haggarty SJ, Katsanis N, Gusella JF, Talkowski ME (2014) CHD8 regulates neurodevelopmental pathways associated with autism spectrum disorder in neural progenitors. Proc Natl Acad Sci U S A 111: E4468-E4477. CrossRef Medline

Sun Y, Goderie SK, Temple S (2005) Asymmetric distribution of EGFR receptor during mitosis generates diverse CNS progenitor cells. Neuron 45:873-886. CrossRef Medline

Tange TØ, Shibuya T, Jurica MS, Moore MJ (2005) Biochemical analysis of the EJC reveals two new factors and a stable tetrameric protein core. RNA 11:1869-1883. CrossRef Medline

Tarpey PS, Raymond FL, Nguyen LS, Rodriguez J, Hackett A, Vandeleur L, Smith R, Shoubridge C, Edkins S, Stevens C, O'Meara S, Tofts C, Barthorpe S, Buck G, Cole J, Halliday K, Hills K, Jones D, Mironenko T, Perry $\mathrm{J}$, et al. (2007) Mutations in UPF3B, a member of the nonsensemediated mRNA decay complex, cause syndromic and nonsyndromic mental retardation. Nat Genet 39:1127-1133. CrossRef Medline

Togi S, Shiga K, Muromoto R, Kato M, Souma Y, Sekine Y, Kon S, Oritani K, Matsuda T (2013) Y14 positively regulates TNF- $\alpha$-induced NF- $\kappa$ B transcriptional activity via interacting RIP1 and TRADD beyond an exon junction complex protein. J Immunol 191:1436-1444. CrossRef Medline Vasistha NA, García-Moreno F, Arora S, Cheung AFP, Arnold SJ, Robertson EJ, Molnár Z (2014) Cortical and clonal contribution of Tbr2 expressing progenitors in the developing mouse brain. Cereb Cortex. Advance online publication. Retrieved June 13, 2014. doi: 10.1093/cercor/bhu125.

Visel A, Thaller C, Eichele G (2004) GenePaint.org: an atlas of gene expression patterns in the mouse embryo. Nucleic Acids Res 32:D552-D556. CrossRef Medline

Xie Y, Jüschke C, Esk C, Hirotsune S, Knoblich JA (2013) The phosphatase $\mathrm{PP} 4 \mathrm{c}$ controls spindle orientation to maintain proliferative symmetric divisions in the developing neocortex. Neuron 79:254-265. CrossRef Medline

Yingling J, Youn YH, Darling D, Toyo-Oka K, Pramparo T, Hirotsune S, Wynshaw-Boris A (2008) Neuroepithelial stem cell proliferation requires LIS1 for precise spindle orientation and symmetric division. Cell 132:474-486. CrossRef Medline 